ARTICLE

DOI: $10.1038 / \mathrm{s} 41467-017-02756-\mathrm{x}$

\title{
Multiple signaling kinases target Mrc1 to prevent genomic instability triggered by transcription- replication conflicts
}

\author{
Alba Duch¹, Berta Canal ${ }^{1}$, Sonia I. Barroso², María García-Rubio², Gerhard Seisenbacher ${ }^{1}$, Andrés Aguilera², \\ Eulàlia de Nadal $^{1} \&$ Francesc Posas ${ }^{1}$
}

Conflicts between replication and transcription machineries represent a major source of genomic instability and cells have evolved strategies to prevent such conflicts. However, little is known regarding how cells cope with sudden increases of transcription while replicating. Here, we report the existence of a general mechanism for the protection of genomic integrity upon transcriptional outbursts in $\mathrm{S}$ phase that is mediated by Mrc1. The $\mathrm{N}$-terminal phosphorylation of Mrc1 blocked replication and prevented transcription-associated recombination (TAR) and genomic instability during stress-induced gene expression in $\mathrm{S}$ phase. An unbiased kinome screening identified several kinases that phosphorylate Mrc1 at the $\mathrm{N}$ terminus upon different environmental stresses. Mrc1 function was not restricted to environmental cues but was also required when unscheduled transcription was triggered by low fitness states such as genomic instability or slow growth. Our data indicate that Mrc1 integrates multiple signals, thereby defining a general safeguard mechanism to protect genomic integrity upon transcriptional outbursts.

\footnotetext{
${ }^{1}$ Cell Signaling Research Group, Departament de Ciències Experimentals i de la Salut, Universitat Pompeu Fabra (UPF), E-08003 Barcelona, Spain. ${ }^{2}$ Centro Andaluz de Biología Molecular and Medicina Regenerativa-CABIMER, Universidad de Sevilla, 41092 Seville, Spain. Alba Duch and Berta Canal contributed equally to this work. Correspondence and requests for materials should be addressed to E.d.N. (email: eulalia.nadal@upf.edu) or to F.P. (email: francesc.posas@upf.edu)
} 
T ranscription-replication conflicts are a major source of genomic instability ${ }^{1,2}$. During $S$ phase, transcription coexists in time and space with DNA replication, and therefore, the two processes must be coordinated to prevent transcription-replication conflicts. S phase is the period of the cell cycle that is the most susceptible to the accumulation of DNA lesions because the unwrapped structure of chromatin in $\mathrm{S}$ phase makes DNA more vulnerable to internal and external mutagenic agents ${ }^{3}$. Moreover, the DNA replication machinery must cope with multiple obstacles that impede replication fork progression leading to double-strand breaks (DSBs) and unscheduled recombination events that challenge genomic integrity ${ }^{4,5}$. One of the most important blocks that the replisome must overcome is the transcription machinery. The collision between replication and transcription machineries results in replication fork stalling that leads to transcription-associated recombination (TAR) and a

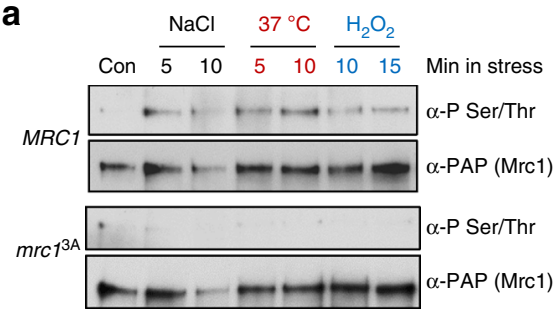

C

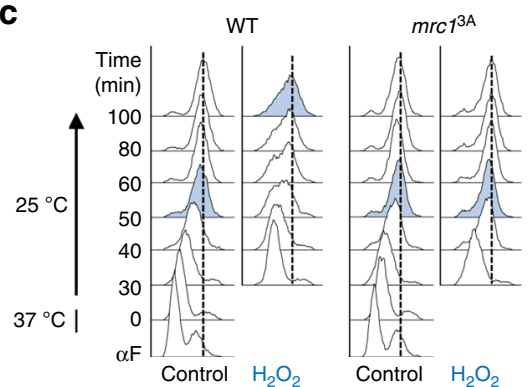

e

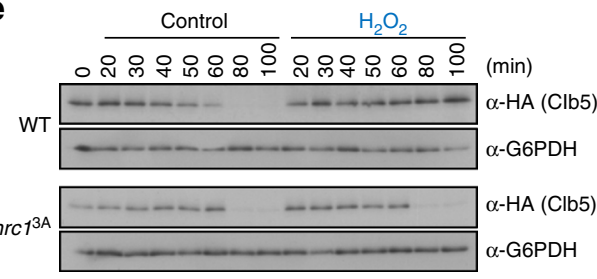

g

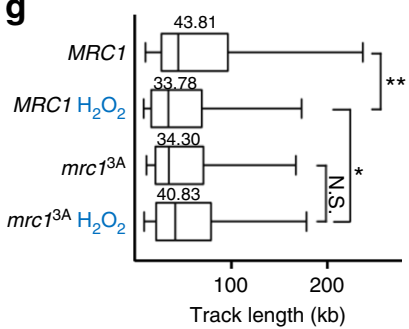

b

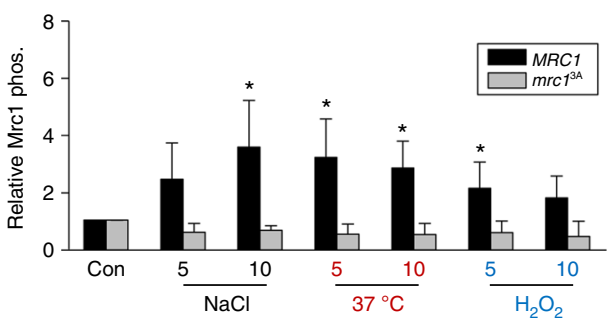

d

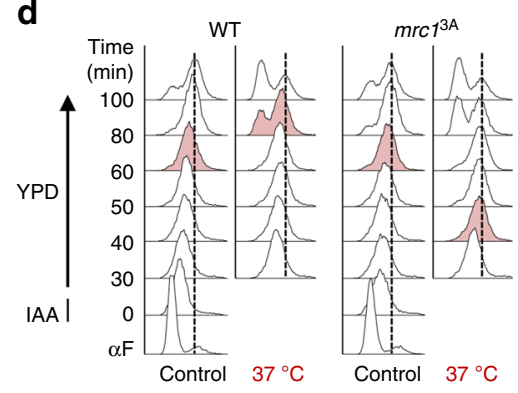

f

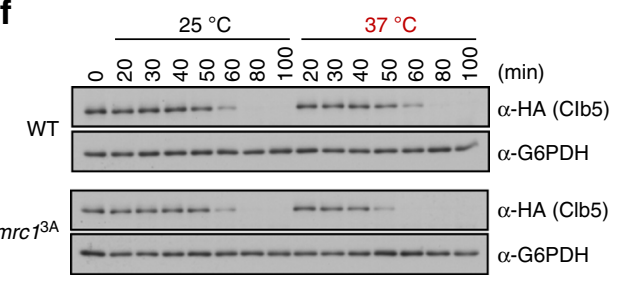

h

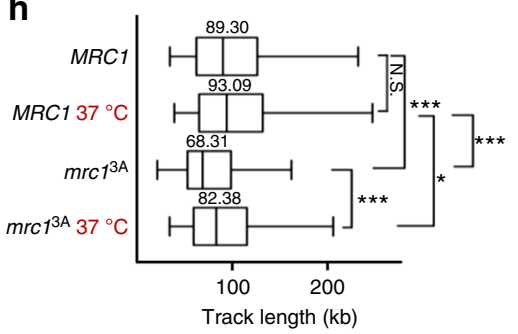

Fig. $1 \mathrm{Mrc1}$ is phosphorylated upon stress to delay DNA replication. a Mrc1 is phosphorylated upon osmotic, heat, and oxidative stresses and mrc $1^{3 \mathrm{~A}}$ protein suppresses this phosphorylation. Mrc1-TAP and $m r c 1^{3 \mathrm{~A}}$-TAP protein were immunoprecipitated (IP) from cells subjected to several stresses and phosphorylation was assessed by western blotting using $\alpha$-phospho Ser/Thr antibodies. Total Mrc1-TAP protein levels were assessed using the anti-PAP antibody. Con control. $\mathbf{b}$ The graphs indicate the relative phosphorylation of Mrc1 and $\mathrm{mrc}^{3 \mathrm{~A}}$ (assessed as in $\mathbf{a}$ ) normalized to the total amount of precipitated Mrc1-TAP protein and then referenced to the control conditions. The data represent the mean and standard deviation of three independent experiments. Values that are significantly different (respect to the control conditions) from Student's $t$ test are indicated by asterisks ( ${ }^{*} p<0.05$ ). $\mathbf{c}$, $\mathbf{d}$ Oxidative (c) and heat (d) stresses cause a delay in cell cycle progression that is abolished in the $m r c 1^{3 \mathrm{~A}}$ cells. Cells were synchronized at the beginning of $\mathrm{S}$ phase as described (see "Methods" section) and released into $\mathrm{S}$ phase at $25^{\circ} \mathrm{C}$ in YPD (control) or in the presence of oxidative (c) or heat stress (d). DNA replication was assessed using FACS. The vertical dotted lines indicate the end of $S$ phase $(2 \mathrm{C}$ peak) and the colored plots indicate the time point at which cells have reached the $2 \mathrm{C}$ peak. IAA indole acetic acid, $\alpha-\mathrm{F}$ pheromone $(\mathbf{e}, \mathbf{f}) \mathrm{mrc}^{3 \mathrm{~A}}$ cells do not delay $\mathrm{Clb} 5$ degradation upon oxidative $(\mathbf{e})$ or heat $(\mathbf{f})$ stress, in contrast to wild-type cells. Cells were treated as in $\mathbf{c}$ and $\mathbf{d}$ and analyzed using western blotting. $\alpha$-G6PDH, loading control. $\mathbf{g}$, $\mathbf{h}$ Replication fork progression is slowed down upon stress. DNA from cells treated as in $\mathbf{c}$ and $\mathbf{d}$ was assessed by combing analysis of replication forks in WT and $m r c 7^{3 A}$ cells in control conditions or upon oxidative and heat stresses, as indicated, after their release into $\mathrm{S}$ phase. The graphs indicate the distribution of BrdU track length $(\mathrm{kb})$ upon oxidative and heat stress during 30 and $15 \mathrm{~min}$ of labeling, respectively. Box, 25-75 percentile range; Whiskers, 5-95 percentile range; ${ }^{\star}$ Values significantly different $\left({ }^{\star} p<0.05,{ }^{\star *} p<0.01\right)$ as determined by the Mann-Whitney $U$ test 
genomic instability. These phenomena highlight the relevance of coordinating replication and transcription for maintaining genomic integrity ${ }^{1,2,6-12}$.

Cells are constantly exposed to environmental changes. The maintenance of cell viability upon sudden changes in osmolarity, temperature, $\mathrm{pH}$, nutrient supply, or oxidative stress is critical for any living organism. To cope with these changes, cells have evolved sophisticated signal transduction pathways that control many aspects of cell physiology, including the control of gene expression $^{13,14}$. For instance, yeast cells trigger a common transcriptional response called the environmental stress response (ESR) when exposed to a wide variety of environmental stresses ${ }^{15}$. This transcriptional program consists of the rapid induction of more than 300 genes that play roles in many physiological functions. Although the ESR is essential for maximizing cell fitness, such massive changes in gene expression pose a risk to genomic integrity when they coincide with DNA replication.

In response to osmostress, the yeast Hog1 MAPK induces hundreds of osmoresponsive genes ${ }^{16,17}$ and, the induction of these osmoresponsive genes can also occur during $\mathrm{S}$ phase. In addition, Hog1 also directly prevents collisions between transcription and replication machineries by phosphorylating the $\mathrm{N}$ terminal region of $\mathrm{Mrcl}$ to block DNA replication. Mrcl is a basic regulatory component of the replication complex that links the helicase with DNA polymerase activities ${ }^{18-21}$ and, it is crucial to maintain an adequate replication fork progression rate ${ }^{18}$. This phosphorylation prevents TAR and subsequent genomic instability upon osmostress ${ }^{22,23}$. Remarkably, this mechanism operates independently of the known DNA damage checkpoint pathway that responds to DNA damage and replication stress ${ }^{24}$, which points to the necessity of a dedicated S-phase control mechanism to deal with the massive transcription that occurs upon osmostress. Therefore, since other environmental stresses also induce massive changes in gene expression, which are not controlled by Hog1, there may be another mechanism(s) that protects genomic integrity and prevents transcription-replication conflicts upon these other stress-dependent transcriptional outbursts.

Here, we show that several stresses provoked a delay in $S$ phase that was mediated by the N-terminal phosphorylation of Mrc1. Mrc1 was phosphorylated by several signaling kinases and its phosphorylation served to prevent TAR and genomic instability and to maximize cell viability. Of note, Mrcl function was not restricted to environmental stresses but was also necessary to prevent TAR and genomic instability upon transcription triggered by mutations that compromise cell fitness. Therefore, we propose that there exists a general S-phase control mechanism that is mediated by Mrc1, which we call the "Mrc1 transcription-replication safeguard mechanism" (MTR), that serves to prevent genomic instability triggered by transcription-replication conflicts that are caused by unscheduled transcription during $S$ phase.

\section{Results}

Mrc1 phosphorylation upon stress delays replication. Several stresses (e.g., heat or oxidative stress) elicit significant changes in gene expression (ESR) similar to those observed upon osmostress. In yeast, $\mathrm{Mrcl}$ is phosphorylated by Hog1 upon osmostress ${ }^{23}$. To assess whether $\mathrm{Mrcl}$ is phosphorylated in vivo in response to other stresses, Mrc1-TAP was immunoprecipitated from cells subjected to osmotic, heat, or oxidative stress and its phosphorylation was analyzed by western blotting with anti-pSer/Thr antibodies. Mrcl was phosphorylated under all stress conditions tested (Fig. 1a). This phosphorylation occurred on the Hog1specific phosphorylation sites (T169, S215, and S229) since it was abolished in cells carrying a mutant allele in these three sites $\left(m r c 1^{3 A}\right)$ (Fig. 1a, b). Thus, different stresses elicit the phosphorylation of the same $\mathrm{N}$-terminal sites in Mrc1. Of note, this phosphorylation did not cause a mobility shift neither in wildtype nor in $m r c 1^{3 A}$ cells, while it did in HU-treated cells, suggesting that $\mathrm{HU}$ promotes phosphorylation of alternative sites different from those caused by stress (Supplementary Figure 1A).

We next assessed the relevance of the N-terminal phosphorylation of Mrcl upon different stresses for cell cycle progression. For analysis of $\mathrm{H}_{2} \mathrm{O}_{2}$ stress, the cells were synchronized at the onset of $\mathrm{S}$ phase by presynchronizing a temperature-sensitive CDC7 allele $\left(c d c 7^{t s 4}\right)$ using pheromone and the cells were subsequently released from this $\mathrm{S}$-phase block at permissive temperature into media with or without $\mathrm{H}_{2} \mathrm{O}_{2}$. S-phase progression was delayed upon oxidative stress compared to nonstressed cells and this delay was not observed in cells carrying the nonphosphorylatable $M R C 1$ allele, $m r c 1^{3 A}$ (Fig. 1c). For analysis of heat stress, pheromone presynchronized cells were arrested at S-phase onset using the $c d c 7^{A I D}$ (auxin-induced degron) system before their release at $25^{\circ} \mathrm{C}$ or at $37^{\circ} \mathrm{C}$ (heat stress). As expected, both the $M R C 1$ wild-type and mutant strains progressed faster into $\mathrm{S}$ phase at $37^{\circ} \mathrm{C}$ than at $25^{\circ} \mathrm{C}$; however, cells carrying the $m r c 1^{3 A}$ allele progressed faster than wild-type cells suggesting that phosphorylation of $\mathrm{Mrcl}$ leads to a delay in replication upon heat stress (Fig. 1d). Clb5 is degraded after cells exit the S phase $^{25,26}$. Of note, no differences in cell cycle progression were observed for the $m r c 1^{3 A}$ cells when compared to wild type in the absence of stress in contrast to mrcl cells that progressed more slowly (Supplementary Figure 2). To support the FACS data, we therefore monitored Clb5 protein expression under the same experimental conditions using cells expressing endogenously HAtagged Clb5. Wild-type cells subjected to oxidative stress showed a clear delay in Clb5 degradation that was not observed in $m r c 1^{3 A}$ cells (Fig. 1e). Similarly, Clb5 was degraded earlier in $m r c 1^{3 A}$ cells subjected to heat stress than in wild-type cells (Fig. 1f). Of note, $\mathrm{HU}$ induces a slight increase on Mrcl phosphorylation since multiple sites (AQ/TQ), different from those targeted by Hog1, are known to be phosphorylated by $\mathrm{Mecl}$ in response to $\mathrm{HU}$. However, HU stimulates a clear mobility shift in a PAGE gel on Mrcl that occurs both in wild-type and $m r c 1^{3 A}$ cells $^{23}$ which was not observed upon osmostress (Fig. 1a and Supplementary Figure 1A). Furthermore, we assessed cell cycle progression in $m r c 1^{A Q}$ (a mutant that contains the Mec1 sites mutated to alanine) and the $m r c 1^{3 A}$ in response to replication stress (HU) and osmostress. We found that while $m r c 1^{3 A}$ cells were arrested upon HU, they did not arrest upon osmostress and in contrast, $m r c 1^{A Q}$ cells were competent to arrest upon osmostress but not in response to HU (Supplementary Figure $1 \mathrm{~B}$ and Supplementary Figure 1C). These results supported that N-terminal phosphorylation of $\mathrm{Mrcl}$ delays S-phase progression upon oxidative and heat stresses as it does for osmostress.

To further determine that N-terminal phosphorylation of Mrc1 delays DNA replication upon heat or oxidative stress, we performed DNA-combing experiments using synchronous cultures to measure replication fork (RF) progression (track length). In contrast to $m r c 1^{3 A}$ cells, wild-type cells showed significantly shorter replication tracks upon oxidative stress, indicating a delay in RF progression (Fig. 1g). Upon heat stress, wild-type cells showed similar RF progression at $25^{\circ} \mathrm{C}$ and $37^{\circ} \mathrm{C}$ in contrast to $m r c 1^{3 A}$ cells in which the RF progressed faster at $37^{\circ} \mathrm{C}$ (Fig. 1h). Of note, the track length in both wild-type and $m r c 1^{3 A}$ cells was significantly higher than that in Fig. 1g, suggesting the possibility of fusions of adjacent replicons. These data indicated that the delay observed in cell cycle progression upon oxidative and heat stresses due to $\mathrm{Mrcl}$ phosphorylation was caused by altered DNA replication. 
a

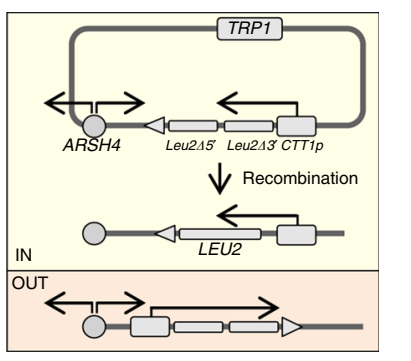

b

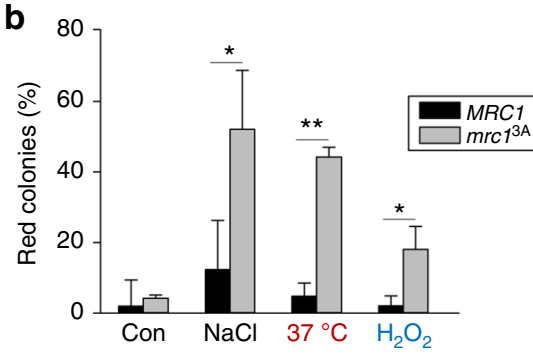

d
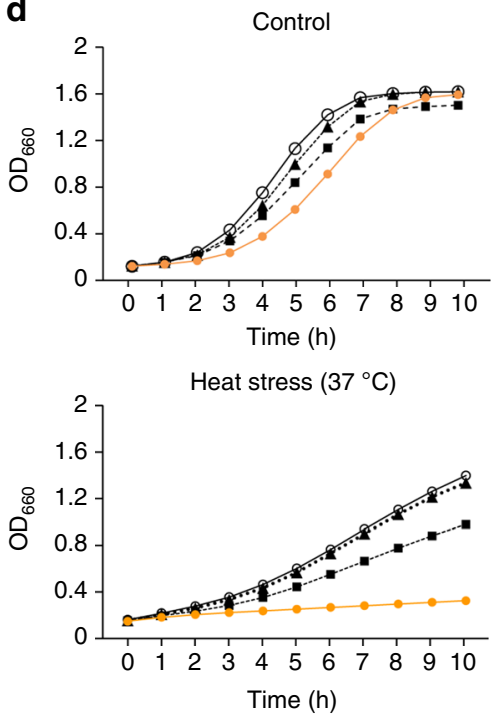
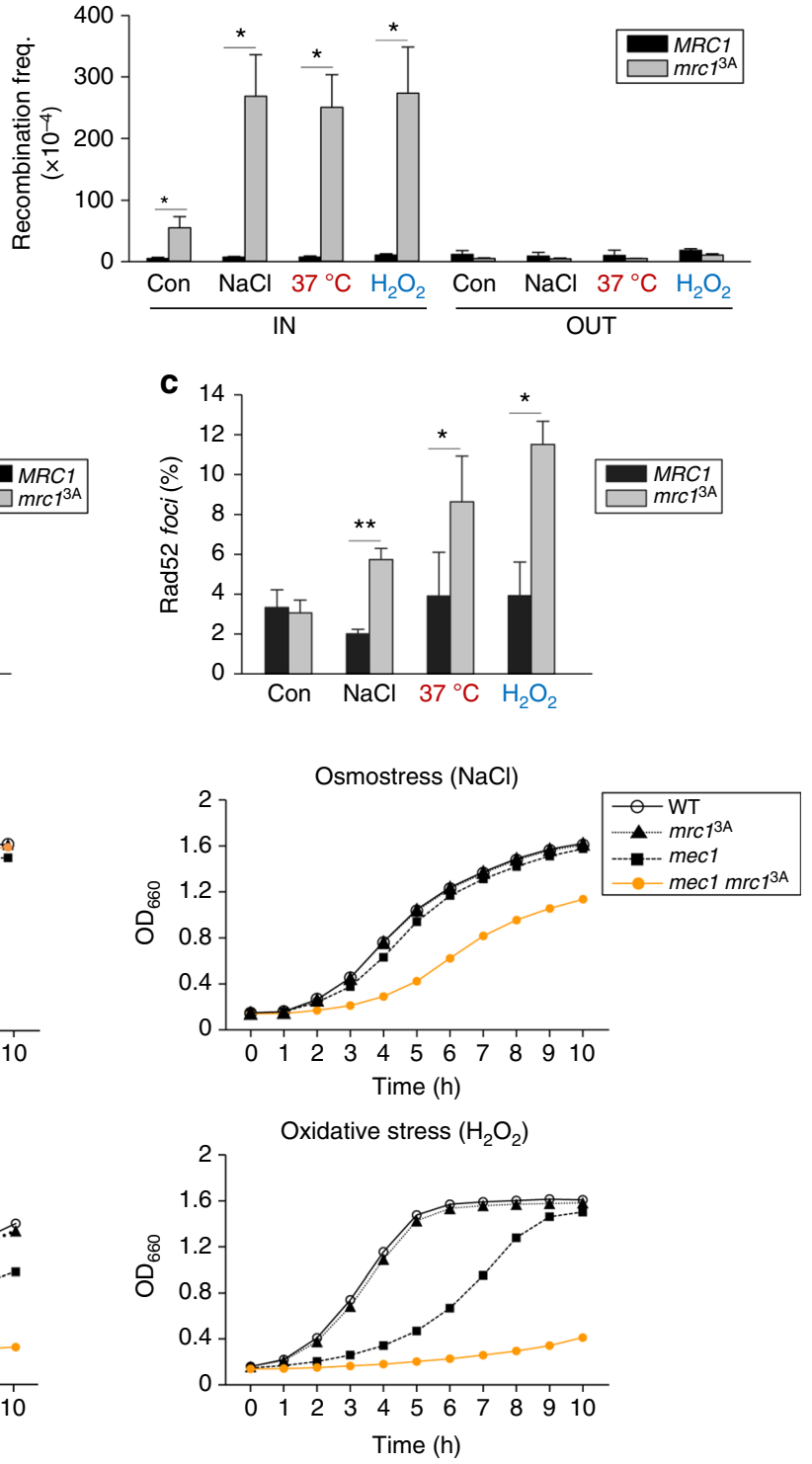

Fig. 2 Mrc1 phosphorylation prevents TAR and genomic instability. a Schematic diagram of the IN/OUT vectors used in the TAR assays. mrc1 $1^{3 A}$ cells display higher levels of recombination than wild-type cells in TAR assays upon release of synchronized cells from S-phase block into osmotic, heat stress, and oxidative stresses (see Methods). $\mathbf{b}$ mrc $7^{3 \mathrm{~A}}$ cells show higher frequency of plasmid loss upon release of synchronized cells from S-phase block into environmental stresses in a red-sectoring assay (see "Methods" section). c mrc ${ }^{3 \mathrm{~A}}$ cells display a higher percentage of Rad52-YFP foci upon release of synchronized cells from S-phase block into environmental stresses. Data in $\mathbf{a}, \mathbf{b}$, and $\mathbf{c}$ represent the mean and standard deviation of three independent experiments. Values that are significantly different $\left({ }^{\star} p<0.05,{ }^{\star \star} p<0.01,{ }^{\star \star \star} p<0.005\right)$ from Student's $t$ test are annotated. $\mathbf{d}$ mrc ${ }^{3 \mathrm{~A}}$ cells show a synthetic cell growth defect with mec1 deletion upon stress. The indicated strains were grown to log phase and subjected to the indicated stresses

Mrc1 phosphorylation prevents transcription-replication conflicts. Induction of gene expression is a major adaptive response to stress. When this transcription is coincident with ongoing replication, it could provoke transcription-replication conflicts resulting in TAR and genomic instability ${ }^{2,27}$. We therefore asked whether TAR increased upon oxidative or heat stress. To measure TAR, we assessed the recombination of a leu2 direct repeat whose transcription was driven by the CTT1 stressresponsive promoter, a prototypical gene of the ESR that responds to osmo, heat, and oxidative stress, which was oriented IN or OUT with respect to the autonomously replicating sequence (ARS)209 (ARSH4). In the absence of stress, neither wild-type nor $m r c 1^{3 A}$ cells showed an increase in TAR. Albeit under control conditions, the $m r c 1^{3 A}$ cells already displayed a certain increase in recombination upon stress, and TAR was strongly induced only in $m r c 1^{3 A}$ cells when transcription and replication progressed in a head-on orientation (IN) in all stresses tested (Fig. 2a). Therefore, N-terminal phosphorylation of Mrc1 is a key factor for the prevention of TAR upon stress.

We next asked how important it was for the cell to delay Sphase progression and prevent TAR upon stress. We assessed chromosomal instability upon stress in wild-type or $m r c 1^{3 A}$ cells using a red-sectoring assay (see "Methods" section). $m r c 1^{3 A}$ cells displayed a clear increase in chromosomal instability in response to stress that was not observed in wild-type cells (Fig. 2b). We then monitored Rad52 foci to measure recombination events in the genome. Cells containing Rad52-GFP were subjected to osmotic, heat, or oxidative stress and Rad52 foci were assessed using microscopy. As expected, stressed $m r c 1^{3 A}$ cells, but not stressed wild-type cells, displayed an increase in Rad52 foci 
compared to control (Fig. 2c). These data indicated that Nterminal phosphorylation of Mrcl is important for maintaining genomic integrity upon stress.

We previously showed that the genomic instability of $\mathrm{mrcl}^{3 \mathrm{~A}}$ cells upon osmostress did not render the cells osmosensitive unless it was in combination with mutations in the DNA damage checkpoint, which prevent the lethal accumulation of the molecular events that are responsible for genomic instability ${ }^{23}$. Similarly, in the present study, deletion of the $M E C 1$ gene, which encodes a serine threonine kinase that can activate the DNA damage checkpoint, or the $m r c 1^{3 A}$ mutation, did not affect cell growth in the presence of other stresses (heat or oxidative). However, its synthetic combination $\left(\mathrm{mecl} \mathrm{mrcl}^{3 \mathrm{~A}}\right)$ resulted in cells that were heat or oxidative stress sensitive (Fig. 2d). These data suggest that transcription-replication conflicts that occur upon several stresses due to the lack of N-terminal phosphorylation of Mrcl require the DNA damage checkpoint to maintain cell viability.

Mutation of MSN2 and MSN4 prevents transcription-replication conflicts. The ESR is mainly mediated by the Msn2 and Msn4 transcription factors ${ }^{15,28}$. Since the expression of the CTT1 ESR gene is controlled by these transcription factors, we assessed TAR in both $m r c 1^{3 A}$ and $m r c 1^{3 A} m s n 2 m s n 4$ cells. Induction of TAR in $m r c 1^{3 A}$ cells was suppressed by deletion of these transcription factors (Fig. 3a). By assessing Rad52 foci, we then investigated if deletion of these transcription factors had a global effect on the recombination events that occur at the genome upon stress. Similar to its inhibition of TAR, the deletion of MSN2 and MSN4 also strongly reduced Rad52 foci accumulation upon different stresses (Fig. 3b). These data indicated that inhibition of the ESR prevents transcription-replication conflicts upon stress.

To assess conflict between transcription and replication at a genomic locus, we performed ChIP analysis of HA-tagged Dpb2, which is the DNA polymerase epsilon catalytic subunit, to follow the progression of DNA polymerase toward the CTT1 gene, which is located at a distance of $4.4 \mathrm{~kb}$ from the ARS727 early origin. ChIP analyses indicated that, under osmostress conditions, DNA polymerase showed delayed binding to the early origin in wild-type cells when released from $S$ phase that was not observed in the $m r c l^{3 A}$ cells (Fig. 3c). As a consequence of this delay, there was also a delay in DNA polymerase reaching the CTT1 locus in wild-type cells upon stress compared to $m r c l^{3 A}$ cells. Despite this delay, the residence time of the DNA polymerase on the CTT1 gene in wild-type cells was similar under the control or the stress condition. In clear contrast, in the $m r c 1^{3 A}$ strain, the presence of stress led to an accumulation of the DNA polymerase on CTT1 that was neither observed in the absence of stress nor in the absence of transcription in the $m r c 1^{3 A} m s n 2 \Delta m s n 4 \Delta$ strain (Fig. 3c). These data show that DNA polymerase encounters problems in proceeding through a highly transcribed genomic locus in $m r c 1^{3 A}$ cells, indicating that Mrcl phosphorylation prevents transcription-replication conflicts in the genome.

Several kinases phosphorylate the $\mathrm{N}$-terminal region of Mrc1. Hog1 is not activated upon heat or oxidative stress (Supplementary Figure 3A). Additionally, deletion of Hog1 does not alter induction of the ESR (Supplementary Figure 3B), and does not lead to an increase in TAR upon heat or oxidative stress (Supplementary Figure 3C). We therefore hypothesized that kinases other than Hog1 might be responsible for the phosphorylation of the N-terminal region of Mrcl upon those stresses. To identify those kinases, we performed an unbiased screen in which we tested 123 tagged-purified yeast protein kinases (see "Methods" section) in an in vitro kinase assay using purified GST-tagged a

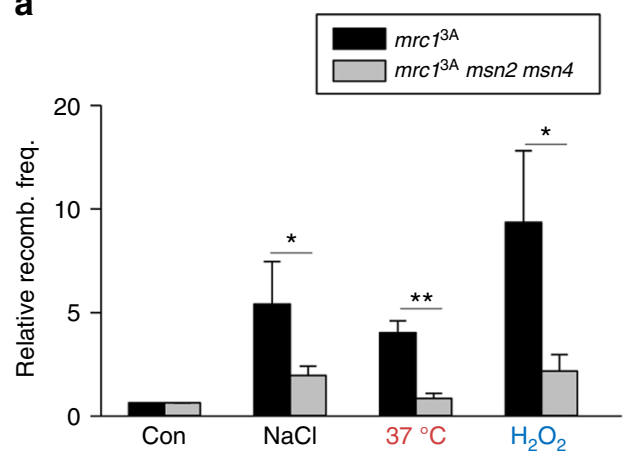

b
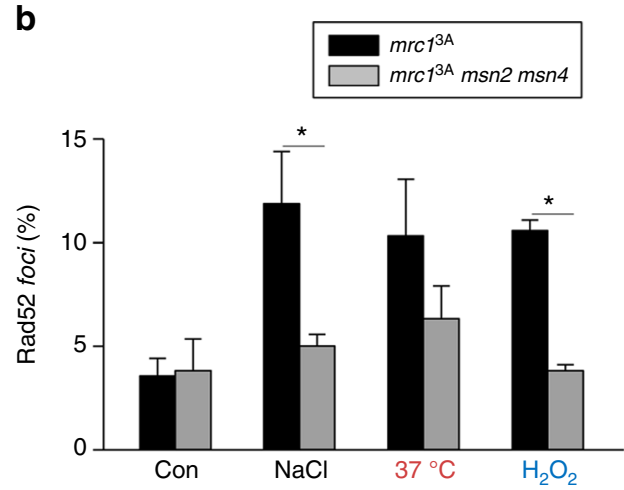

C
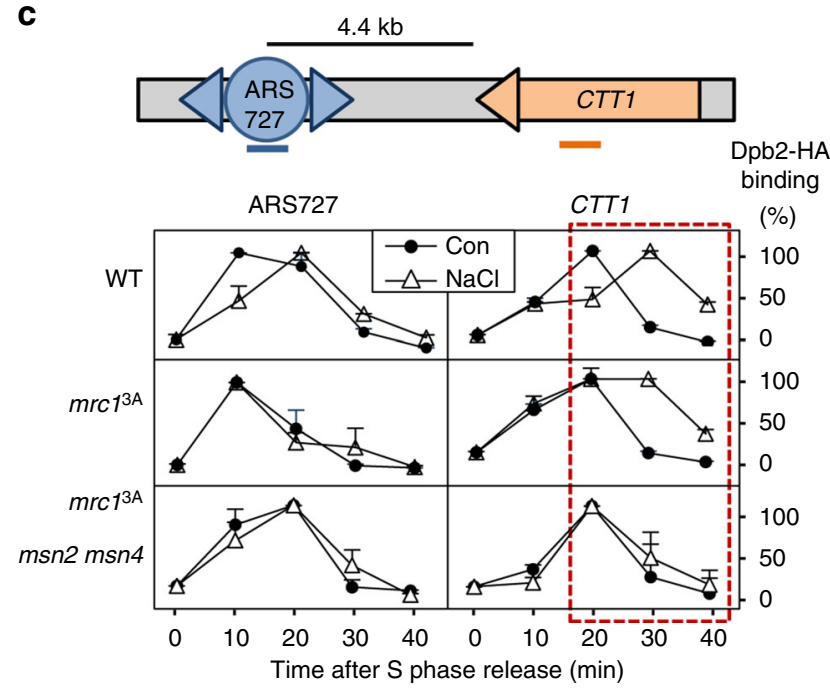

Fig. 3 Genomic instability in $m r c 1^{3 \mathrm{~A}}$ cells depends on transcription. a Deletion of the MSN2 and MSN4 transcription factors suppresses the high TAR levels of the $\mathrm{mrc}^{3 \mathrm{~A}}$ strain upon stress. Numbers are relative to the recombination levels in control conditions. b The $\mathrm{mrcl}^{3 \mathrm{~A}} \mathrm{msn2} \mathrm{msn} 4$ strain displays fewer Rad52-YFP foci than the $\mathrm{mrc}^{3 \mathrm{~A}}$ strain upon stress.

Experiments in $\mathbf{a}$ and $\mathbf{b}$ were performed as in Fig. 2. Data in $\mathbf{a}$ and $\mathbf{b}$ represent the mean and standard deviation of three independent experiments. Values that are significantly different $\left({ }^{\star} p<0.05,{ }^{\star \star} p<0.01\right.$, $\left.{ }^{\star \star *} p<0.005\right)$ by Student's $t$ test are annotated. c DNA polymerase proceeds more slowly across the CTT1 gene upon osmostress in $\mathrm{mrc}^{3 \mathrm{~A}}$ cells when transcription is active. Schematic diagram of the ARS727 and the CTT1 loci. The association of Dpb2-HA at the indicated ARS727 and CTT1 sites (colored bars) was determined using ChIP. Graphs show the kinetics of Dpb2-HA binding after release in YPD (Con) or osmostress $(\mathrm{NaCl})$. The red square highlights the relevant time points. Data represent the mean and standard deviation of three independent experiments 
a

a
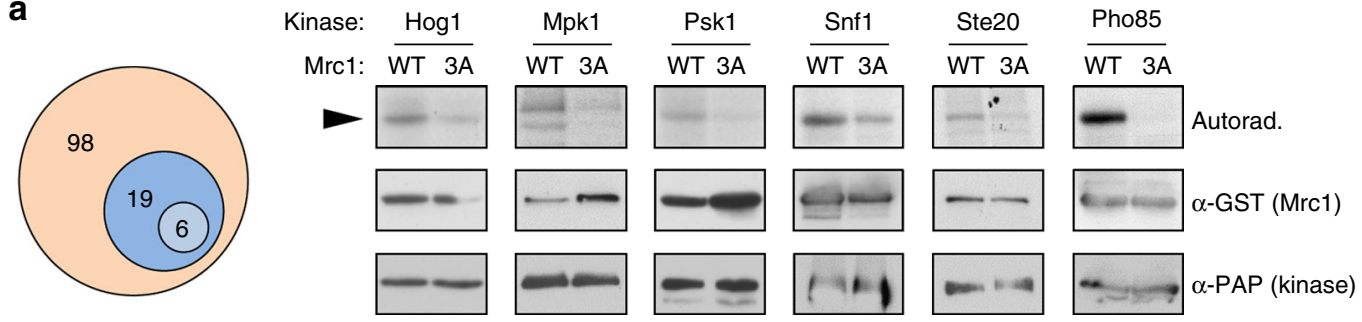

b

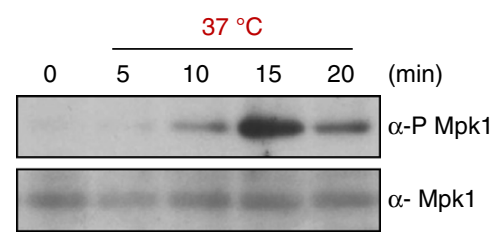

d

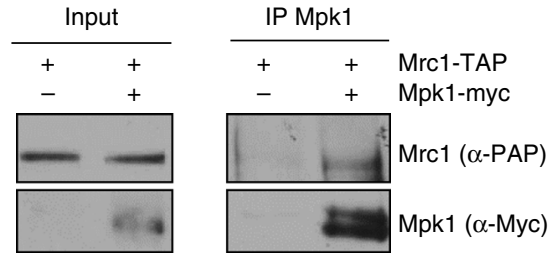

f

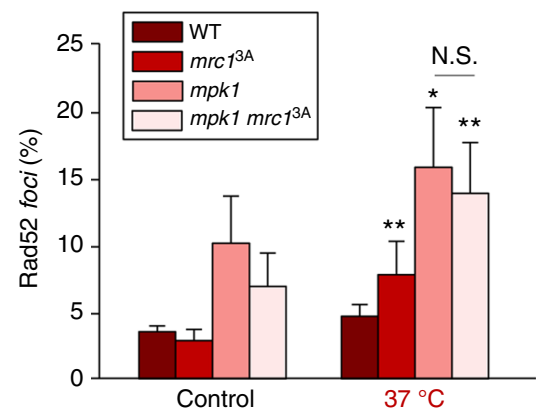

c

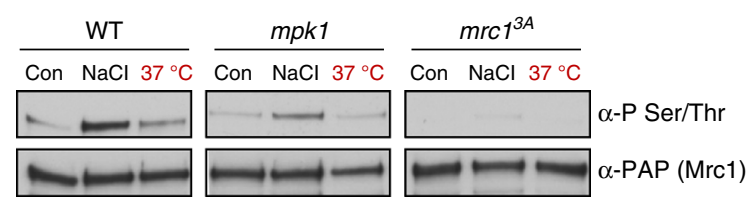

e

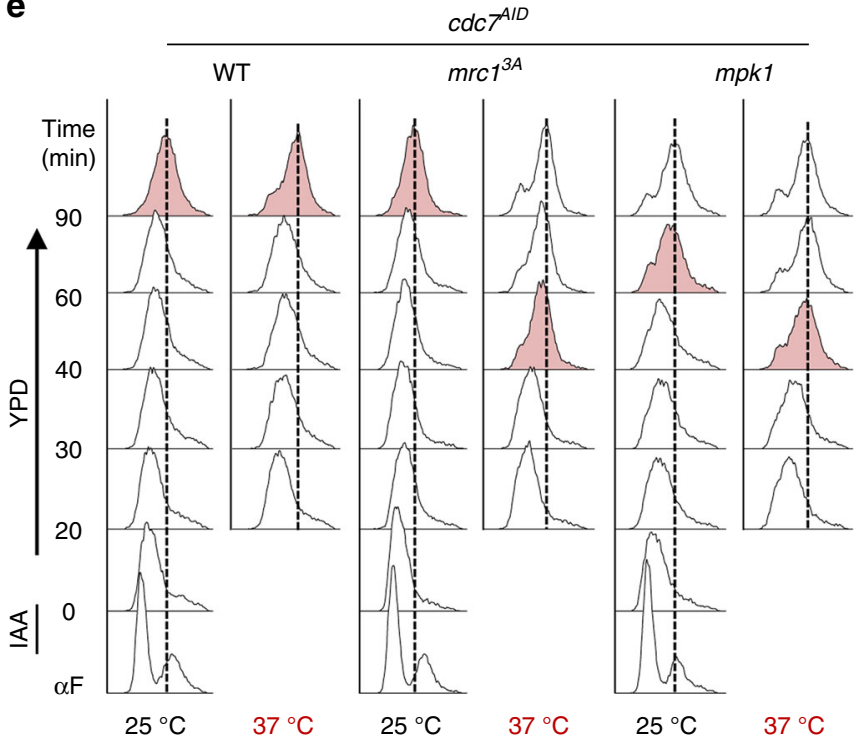

Fig. 4 A kinase screen identified several kinases that phosphorylate the $\mathrm{N}$ terminus of Mrc1. a Six kinases phosphorylate the $\mathrm{N}$ terminus of Mrc1. In the screen, 123 tagged-purified yeast kinases were incubated in an in vitro kinase assay with a fragment (1-360 aa) of Mrc1 or its corresponding mutant in which the three phosphorylation sites Thr169, Ser215, and Ser229 were mutated to alanine ( $m r{ }^{3 A}$ ) (see "Methods" section). Out of these 123 in vivopurified kinases, 25 kinases (in blue) phosphorylated GST-Mrc1 in an in vitro kinase assay. Six of these 25 kinases phosphorylated GST-Mrc1 but not GST$\operatorname{mrc}^{3 \mathrm{~A}}$. b-f Mpk1 kinase mediates the Mrc1-dependent cell cycle delay upon heat stress. b Mpk1 is phosphorylated in vivo upon heat stress. Synchronized cells were released into $\mathrm{S}$ phase and subjected to heat stress. Mpk1 phosphorylation over time was followed by western blotting using specific antibodies. Nonphosphorylated Mpk1 was blotted as a loading control (c) Mrc1 is phosphorylated in vivo by Mpk1 upon heat stress. This experiment was carried out as in Fig. 1a and was assayed as in $\mathbf{b}$. $\mathbf{d}$ Mrc1 and Mpk1 interact in vivo. Mrc1-TAP was immunoprecipitated (IP) from cells and coprecipitated Mpk1-myc was assayed using western blotting. e mpk1 cells bypass the DNA replication delay caused by heat stress. Pheromone presynchronized cells were arrested at Sphase onset using the $c d c 7^{A I D}$ (auxin-induced degron) system before their release at $37^{\circ} \mathrm{C}$ (heat stress). DNA replication over time was followed using FACS. $\mathbf{f m k} 1$ cells display a higher percentage of Rad52-YFP foci upon heat stress. Data represent the mean and standard deviation of three independent experiments. Asterisks indicate statistically significant differences by Student's $t$ test $\left({ }^{\star} p<0.05,{ }^{\star \star} p<0.01,{ }^{\star \star \star} p<0.005\right)$ of stress versus control conditions

Mrc1 or $\mathrm{Mrc1}^{3 \mathrm{~A}}$ (amino acids 1-360). This screen yielded 25 kinases that phosphorylated Mrc1, of which only six kinases were able to phosphorylate the wild-type Mrc1 but could not phosphorylate the $\mathrm{Mrcl}^{3 \mathrm{~A}}$ mutant (Fig. 4a). One of these six kinases was Hog1, which served as an internal control for the in vitro screen. Mpk1 was identified in this screen as one of the six kinases that can specifically phosphorylate the $\mathrm{N}$-terminal sites of the wild-type Mrc1. Mpk1 is activated in response to high temperatures and it has been implicated in the heat stress response ${ }^{29}$. We therefore tested whether Mpk1 is involved in the regulation of Mrcl upon heat stress. We assayed Mpk1 phosphorylation (activation) in synchronized cells that were released into $S$ phase and then subjected to heat stress. Mpk1 was rapidly phosphorylated under these in vivo conditions (Fig. $4 \mathrm{~b}$ and S4A). Heat stress-induced Mrcl phosphorylation was abolished in both $m r c 1^{3 A}$ and $m p k 1$ mutants, suggesting that Mpk1 phosphorylates the N-terminal region of Mrcl upon heat stress (Fig. 4c, Supplementary Figure 4A, Supplementary Figure 4B, and Supplementary Figure 4C). We next tested whether Mpk1 and Mrcl can directly interact by performing immunoprecipitation experiments using cells expressing endogenously Myc-tagged Mpk1 and TAPtagged Mrc1. TAP-tagged Mrcl coprecipitated with Myc-tagged Mpk1 (Fig. 4d), indicating that Mrc1 is a bona fide target of Mpk1.

To assess the role of Mpk1 in replication upon heat stress, cells were subjected to heat stress after $c d c 7^{A I D}$ synchronization. 
At $37^{\circ} \mathrm{C}$, the cells replicated faster than at $25^{\circ} \mathrm{C}$. However, cells carrying the $m r c 1^{3 A}$ allele or $m p k 1$ mutation progressed faster than wild-type cells, indicating that Mpk1 delays replication upon heat stress (Fig. 4e). We then followed Rad52 foci in these cells under these conditions. Even though the number of foci in $m p k 1$ cells was already higher than that of wild-type cells under nonstress conditions, the number of foci further increased in $m p k 1$ cells upon heat stress. Of note, the synthetic mutation of $m p k 1$ and $m r c 1^{3 A}$ did not lead to a further increase of Rad52 foci upon heat stress (Fig. 4f). These data indicate that Mpk1 kinase is responsible for the regulation of Mrcl to protect genomic stability upon heat stress.

Psk1 targets Mrc1 to delay $\mathrm{S}$ phase upon oxidative stress. The involvement of $\operatorname{Hog} 1$ and Mpk1 in osmostress and heat stress, respectively, led us to test whether some of the other kinases identified in the screen might promote the delay in $S$ phase observed upon oxidative stress. Since Psk1 was proposed to be involved in the oxidative stress response ${ }^{30}$, we tested whether Psk1 was activated under the oxidative stress conditions that had induced S-phase delay. HA-tagged Psk1 showed a clear shift in mobility in a western blot upon oxidative stress that was abolished by alkaline phosphatase (AP) treatment (Fig. 5a). We then assessed whether Psk1 could interact with Mrcl. HA-tagged Psk1 coprecipitated with TAP-tagged Mrc1, indicating a direct interaction of the two proteins (Fig. 5b). Of note, immunoprecipitated HA-Psk1 phosphorylated purified GST-tagged Mrcl more efficiently when activated upon oxidative stress (Fig. 5c). Finally, we assessed in vivo Mrcl phosphorylation in cells upon oxidative stress as before, using wild-type cells or cells deficient in PSK1. The phosphorylation of Mrcl was clearly reduced upon oxidative stress in psk1 cells in comparison with wild-type cells (Fig. 5d). The combined data indicated that the activity of Psk1 is induced upon oxidative stress and, once activated, Psk1 phosphorylates Mrc1.

Since oxidative stress induces a delay in $S$ phase (Fig. 1), we next asked whether Psk1 was involved in the S-phase delay upon oxidative stress. The delay observed in wild-type cells upon $\mathrm{H}_{2} \mathrm{O}_{2}$ treatment was abolished in both $m r c 1^{3 A}$ cells and $p s k 1$ cells, indicating that Psk1 is responsible for the delay in the cell cycle upon oxidative stress (Fig. 5e). We then tested whether Psk1 was relevant for the prevention of TAR upon oxidative stress. Deletion of PSK1 resulted in an increase in TAR upon oxidative stress similar to that observed in $m r c 1^{3 A}$ cells (Fig. 5f). The percentage of Rad52 foci also increased upon oxidative stress to a similar extent in $p s k 1$ and $m r c 1^{3 A}$ cells. Of note, no additivity was observed in the double mutant psk1 $\mathrm{mrcl}^{3 A}$ (Fig. 5g). These data indicated that the Hog1, Mpk1, and Psk1 kinases phosphorylate Mrcl to delay $S$ phase and to protect genomic integrity upon osmotic, heat, and oxidative stress, respectively.

Snf1 regulates Mrc1 upon nutrient deprivation. In addition to osmotic, heat, and oxidative stress, it has been reported that low glucose also induces the ESR program ${ }^{31}$. In this respect, a notable finding of the above kinase screen was that Snf1 phosphorylated the N-terminal sites of Mrc1. Mrcl was phosphorylated in vivo in response to low glucose, and this phosphorylation was abolished in a $s n f 1$ mutant (Fig. 6a, b). Snf1 is the AMP kinase that mediates the cell-adaptive responses to nutrient deprivation ${ }^{32-34}$; however, it has not been previously implicated in the control of S-phase progression. We therefore assessed if $\mathrm{Mrcl}$ might play a role in nutrient deprivation similar to its role in environmental stress. For this purpose, we initially monitored S-phase progression upon low glucose treatment by FACS analysis and monitoring of Clb5 degradation. Low glucose treatment induced a clear delay in cell cycle progression that was almost abolished in $m r c 1^{3 A}$ cells
(Fig. 6c and Supplementary Figure 5A). This finding indicated that the phosphorylation of Mrcl is also relevant for the delay in S-phase progression upon low glucose treatment. We then assessed whether low glucose treatment altered DNA replication by performing DNA combing. Wild-type cells showed significantly shorter replication tracks upon low glucose treatment compared to $\mathrm{mrcl}^{3 \mathrm{~A}}$ cells, which indicates a delay in RF progression in the wild-type cells (Fig. 6d). These data indicated that the delay observed in cell cycle progression upon low glucose treatment is caused by a delay in replication mediated by $\mathrm{Mrc1}$ phosphorylation.

To assess the relevance of this delay for cell adaptation to nutrient deprivation, we assayed the effect of low glucose treatment on TAR in wild-type and $m r c 1^{3 A}$ cells. The $m r c 1^{3 A}$ cells, but not the MRC1 wild-type cells, showed a clear increase in recombination upon nutrient deprivation (Supplementary Figure 5B). In addition, we also assayed chromosomal instability upon low glucose treatment in wild-type or $m r c 1^{3 A}$ cells using a red-sectoring assay. The $m r c 1^{3 A}$ cells displayed a clear increase in chromosomal instability (chromosome loss) under low glucose conditions that was not observed in wild-type cells (Supplementary Figure 5C). Furthermore, the synthetic combination of mec1 $m r c 1^{3 A}$ resulted in cells sensitive to low glucose (Supplementary Figure 5D). These data indicated that the N-terminal phosphorylation of $\mathrm{Mrcl}$ is critical for the maintenance of genomic integrity under low glucose conditions.

Snf1 is activated by phosphorylation at the Thr210 residue ${ }^{35}$. We followed Snf1 phosphorylation over time under our experimental setup and found that Snf1 was clearly phosphorylated (activated) upon low glucose treatment (Fig. 6e). We then monitored the direct interaction of Snfl and Mrc1 in vivo by performing immunoprecipitation experiments using cells expressing HA-tagged Snfl and TAP-Mrcl. HA-Snfl and TAP-Mrc1 were found to coprecipitate, indicating that they interact in vivo (Fig. 6f). To assess the relevance of the Mrc1 phosphorylation by Snf1 in maintaining genomic integrity, we assayed Rad52 foci under low glucose conditions. $m r c 1^{3 A}$ and $s n f 1$ cells displayed a clear increase in Rad52 foci upon low glucose that did not increase in the double mutant $m r c 1^{3 A} s n f 1$ (Fig. 6g), indicating that the phosphorylation of Mrcl by Snfl protects genomic integrity in low glucose.

Mrc1 prevents genomic instability in slow growing and unstable cells. It has been shown that a number of genetic perturbations that result in slower growth rates also display a common expression signature that resembles the $\mathrm{ESR}^{36}$. Similarly, mutations that cause genomic instability also trigger the ESR transcriptional signature ${ }^{37,38}$. We hypothesized that cells carrying mutations that lead to an increased ESR should induce Mrc1 phosphorylation to prevent replication and transcription conflicts during $S$ phase. Initially, using northern blotting, we assessed whether slow-growing cells (i.e., ssn6) or cells displaying genomic instability (i.e., rad53) expressed the CTT1 and ALD3 prototypical ESR genes. Both strains showed higher expression of those genes compared with controls (Fig. 7a and Supplementary Figure 6) consistent with a previous report ${ }^{36}$.

We then assessed whether the mutation of SSN6 or RAD53 resulted in an increase in TAR. The single mutation of SSN6 or RAD53 genes did not significantly induce TAR compared to wildtype cells. However, in clear contrast, the synthetic mutation of $s s n 6$ or rad53 with $m r c 1^{3 A}$ resulted in a clear increase in TAR. As expected, these increases in TAR were completely abolished by mutation of the MSN2 and MSN4 transcription factors that are responsible for the ESR (Fig. 7b). Additionally, the levels of Rad52 foci also clearly increased when ssn 6 or rad53 mutations were 
combined with $m r c 1^{3 A}$ and these increases in foci formation were also abolished by deletion of the MSN2 and MSN4 transcription factors (Fig. 7c). These data therefore suggest that Mrc1 function is not restricted to environmental cues but that Mrc1 also integrates internal signals that induce unscheduled changes in transcription that can lead to transcription-replication conflicts (summarized in Fig. 7d).

\section{Discussion}

Transcription-replication conflicts are a major source of genomic instability. Cells have evolved several mechanisms to coordinate the two processes. However, it is not clear how cells deal with unscheduled outbursts of transcription when these occur in $S$ phase. Here, we show that Mrcl plays a key role in the prevention of transcription-replication conflicts in S phase. In response to a

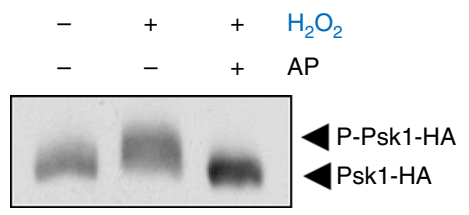

。

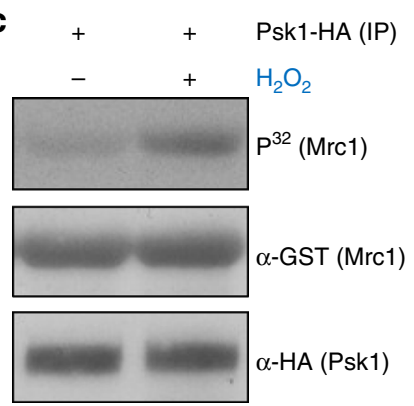

b

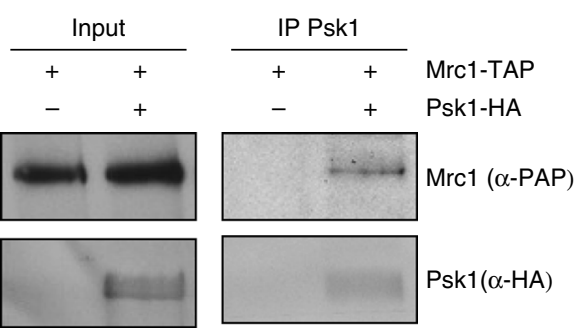

d

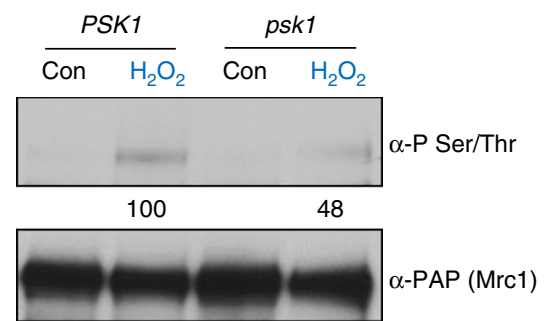

e

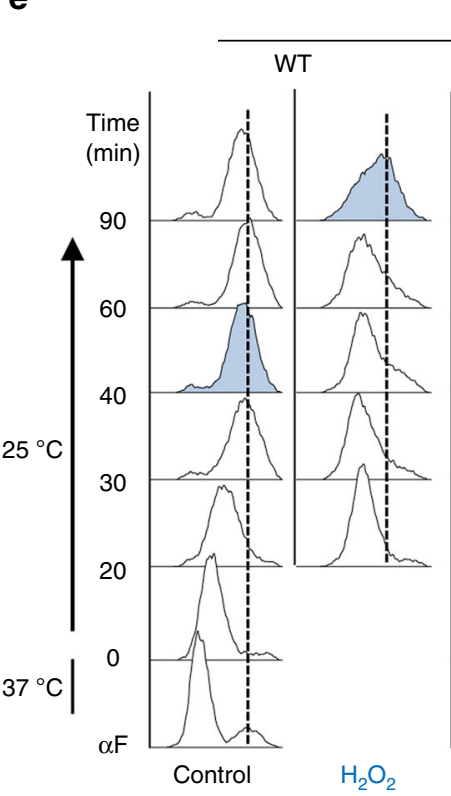

$c d c 7^{t s 4}$
$m r c 1^{3 A}$
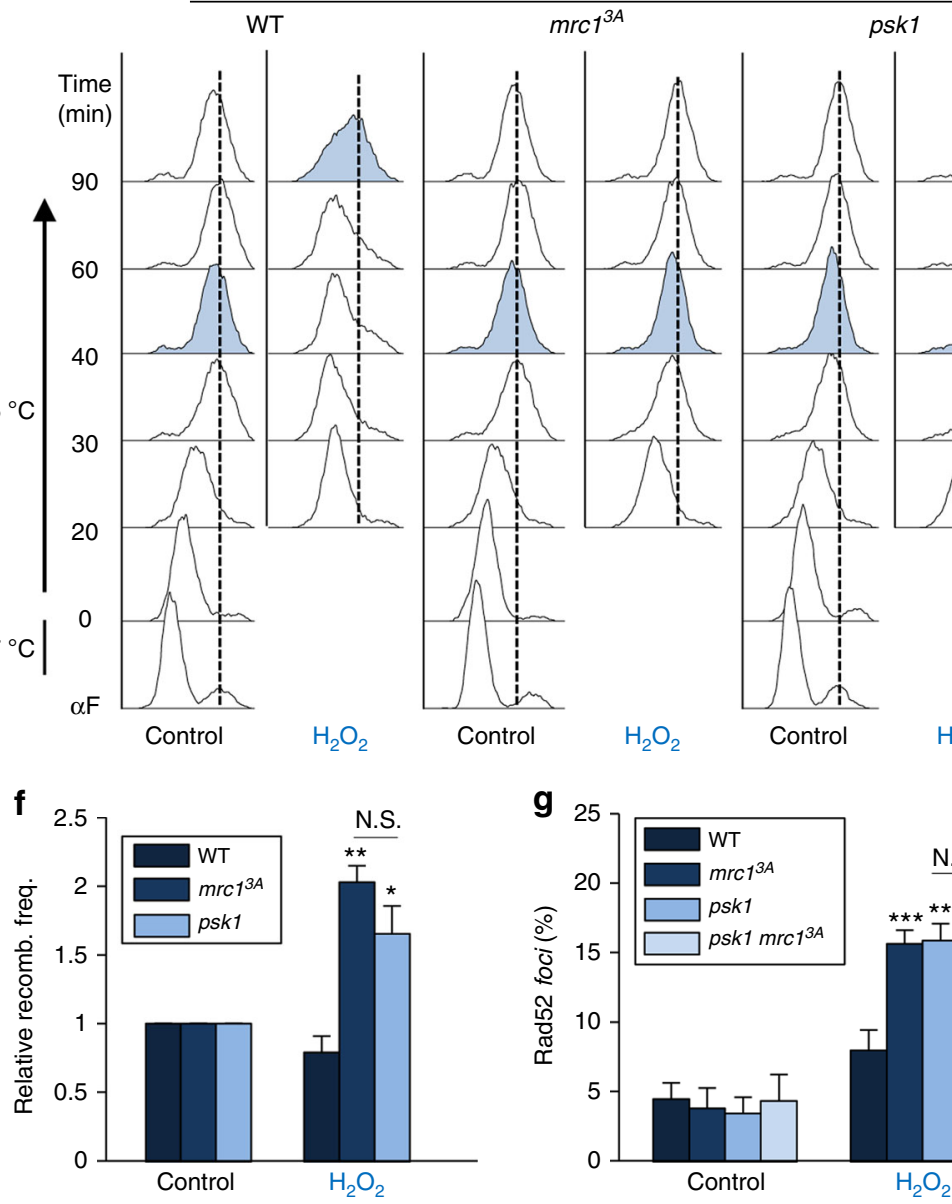

g

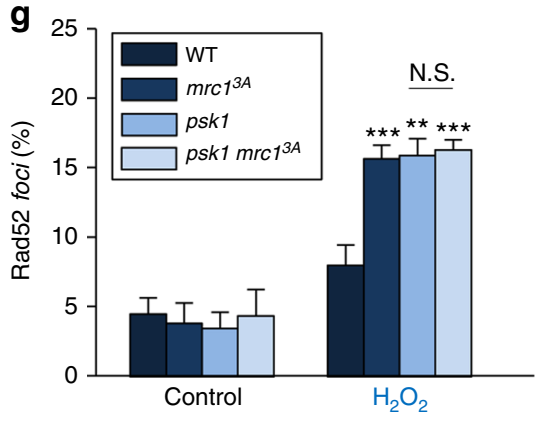


transcriptional outbursts, $\mathrm{Mrcl}$ is phosphorylated in its $\mathrm{N}$ terminal region by multiple kinases and this phosphorylation leads to a delayed cell cycle, prevents TAR, and serves to preserve genomic integrity.

In general, transcription is highly coordinated with replication to prevent encounters between the transcription and replication machineries. However, there are some scenarios, such as environmental insults that might occur during $S$ phase, which require a massive induction of gene expression to maximize cell survival. In contrast to the programmed highly active transcription (i.e., of rRNA) that takes place at loci near the specialized regions of the genome (i.e., replication fork barriers) that prevent transcription-replication conflicts, this unscheduled stressdependent transcription results in the presence of transcription complexes throughout the genome. Thus, in this scenario, it is essential that alternative sophisticated mechanisms exist that can prevent and resolve transcription-replication conflicts. In yeast, the Hog1 SAPK transiently induces hundreds of genes upon osmostress ${ }^{16,39}$. Hog1 also regulates cell cycle progression ${ }^{40-42}$. Within the same temporal framework in which stress-induced transcription occurs during $\mathrm{S}$ phase, Hog1 also phosphorylates Mrc1 at its N-terminal region, which prevents the origin of firing and slows down replication fork progression resulting in a delay in $S$ phase ${ }^{23}$. Of note, in contrast to $m r c 1$-deficient cells which display replication defects and a delay of S-phase progression under normal conditions, $m r c 1^{3 A}$ mutant replicates as the wild type and does not display hallmarks of replication stress. The delay caused by $\mathrm{N}$-terminal phosphorylation upon stress is independent of the DNA damage checkpoint governed by Mec1 and $\operatorname{Rad} 53^{22}$, and is critical for coordination of osmostressinduced transcription with replication. When cells are deficient in the N-terminal phosphorylation of $\mathrm{Mrc1}$, they display an increase in TAR, genomic instability, and reduced viability upon osmostress. We therefore hypothesized that N-terminal phosphorylation of Mrcl might represent a general mechanism by which transcription is coordinated with replication upon sudden transcriptional outbursts. Here, we investigated whether replication might be delayed in order to maintain genomic integrity through such a mechanism upon other stresses that do not activate Hog1 but that do induce sudden changes in gene expression to a similar extent as that induced by osmostress. Indeed, multiple environmental stresses such as heat, oxidative stress, and nutrient limitation, which lead to major changes in gene expression by inducing the ESR, did lead to Mrcl phosphorylation, and this phosphorylation prevented TAR and genomic instability in addition to maximizing cell survival. These results indicated that the N-terminal phosphorylation of Mrcl serves to integrate multiple signals to control replication and prevent transcription-replication conflicts.

By performing an unbiased biochemical screening, we identified six kinases that phosphorylate the $\mathrm{N}$ terminus of $\mathrm{Mrcl}$. Remarkably, most of the kinases identified were signaling kinases, one of which was Hog1. Another of the identified kinases was
Mpk1, which is known to be activated upon heat stress ${ }^{29}$. Here, we show that Mpk1 can phosphorylate Mrcl in response to heat and that this phosphorylation is important for the delay in cell cycle progression and for the prevention of TAR and genomic instability following heat stress. Thus, different MAP kinases, Hog1 in osmostress and Mpk1 in response to heat stress, can phosphorylate the same Mrcl sites. Little is known regarding Psk1 kinase, although it has been suggested to be involved in oxidative stress ${ }^{30}$. Here, we found that deletion of PSK 1 prevented the cell cycle delay that is induced upon oxidative stress and resulted in an increased TAR and genomic instability upon oxidative stress. We therefore concluded that Psk1 is the kinase that prevents transcription-replication conflicts upon oxidative stress, which defines a new role for this kinase. A notable result of the kinase screen was the identification of Snfl as a kinase that can phosphorylate Mrc1. Snf1 is the AMP kinase that is responsible for the cellular response to nutrient deprivation and it is highly conserved across eukaryotes ${ }^{34,43}$. These characteristics of the AMP kinase prompted us to investigate whether low glucose resulted in S-phase arrest and to define the role of Snf1 in cell cycle control. Indeed, low glucose treatment resulted in a clear Snf1-mediated S-phase delay that was due to delayed replication. The genomic instability in cells lacking Snf1 was similar to that in cells expressing $m r c 1^{3 A}$, indicating that Snf1 is a regulator of Sphase progression. Albeit the kinases identified in the screening are able to target $\mathrm{Mrcl}$ in response to their activation and in response to specific stresses, in contrast to Hog1, they do not control the expression of the ESR genes such as CTT1 per se (Supplementary Figure 7). The combined data show that Mrc1 integrates signals from several signaling kinases that are activated upon specific stimuli to coordinate gene expression and replication.

The ESR is induced not only upon stress, but also by mutations that result in slow growth ${ }^{36}$ or cause genomic instability ${ }^{38}$. Thus, ESR seems to be a transcriptional signature for a "low fitness" state that can be caused by both external insults and internal genomic alterations. Since N-terminal Mrcl phosphorylation was clearly required to coordinate ESR induction with replication upon several stresses, we investigated whether Mrcl phosphorylation also served this purpose in response to mutations that lead to slow growth or genomic instability. Remarkably, mutation of SSN6, which results in slow growth ${ }^{36}$, or mutation of RAD53, which results in genomic instability 44,45 , did lead to increases in TAR and Rad52 foci when combined with $m r c 1^{3 A}$. Of note, these effects were totally abolished when Msn2 and Msn4, the transcription factors that control the ESR, were also mutated. Therefore, Mrcl is essential for the prevention of transcription-replication conflicts and the subsequent genomic instability in multiple situations that compromise cell fitness and trigger induction of the ESR transcriptional defense mechanism.

Based on our results, we propose a model (Fig. $7 \mathrm{~d}$ ) in which $\mathrm{Mrc1}$ integrates multiple signals to delay replication. On the one

Fig. 5 Psk1 mediates the Mrc1-dependent delay upon oxidative stress. a Psk1 is phosphorylated upon oxidative stress in vivo. In vitro kinase assay of Psk1-HA immunoprecipitated from treated cells. AP alkaline phosphatase. $\mathbf{b}$ Mrc1 and Psk1 interact in vivo. Co-immunoprecipitation of Mrc1-TAP with Psk1-HA was assayed in an in vivo pull-down assay and subsequent western blotting with the indicated antibodies. c Psk1 phosphorylates Mrc1 more efficiently when activated by oxidative stress. The phosphorylation of GST-Mrc1 by HA-Psk1 immunoprecipitated from treated/untreated cells was assayed using an in vitro kinase assay and autoradiography. d Mrc1 is phosphorylated by Psk1 in vivo. This experiment was carried out as in Fig. 1a. Numbers indicate the percentage of phosphorylation relative to loading and the signal of Mrc1 phosphorylation in the wild-type strain. e psk14 cells do not delay $S$ phase upon oxidative stress. DNA replication over time was followed using FACS. $\mathbf{f} p s k 1$ cells display higher levels of TAR upon oxidative stress than wild-type cells. Numbers are relative to recombination levels in control conditions. $\mathbf{g}$ psk1 cells show a higher percentage of Rad52-YFP foci upon oxidative stress. Data represent the mean and standard deviation of three independent experiments. Asterisks indicate statistically significant differences by Student's $t$ test $\left({ }^{\star} p<0.05,{ }^{\star \star} p<0.01,{ }^{\star \star *} p<0.005\right)$ of stress versus control conditions 
hand, Mrc1 is part of the DNA damage checkpoint when targeted by $\mathrm{Mec1}^{19,20}$. Mec1 phosphorylation of Mrcl occurs at different sites from those targeted by the signaling kinases identified in the present study. On the other hand, we show that the N-terminal phosphorylation of $\mathrm{Mrcl}$ serves as a key integrator of multiple signals to block DNA replication and prevent transcription-replication conflicts. The role of this N-terminal phosphorylation of Mrc1 goes beyond environmental stresses since it also integrates internal signals triggered by mutations that compromise cellular fitness. We have therefore defined a new cell cycle control mechanism, which we have named the "Mrc1 transcription-replication safeguard mechanism" (MTR), that protects genomic integrity when outbursts of transcription or unscheduled transcription occur during $S$ phase.

\section{Methods}

Growth media. E. coli strains were grown at $37^{\circ} \mathrm{C}$ in LB (Luria-Bertani) broth containing $1 \%$ bactotryptone, $0.5 \%$ yeast extract, and $1 \% \mathrm{NaCl}$. Plasmids were a

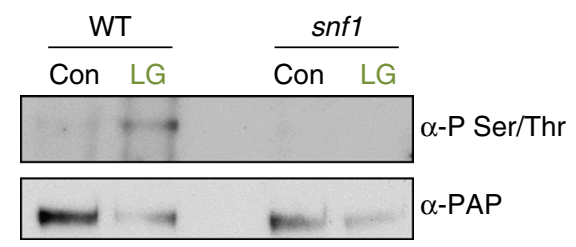

C

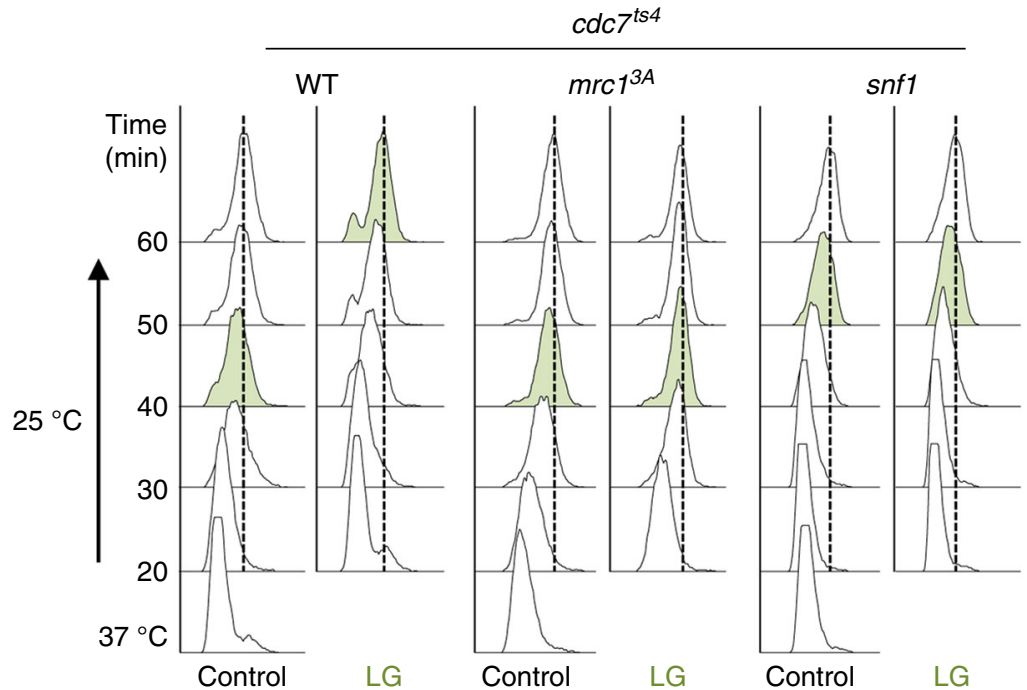

d

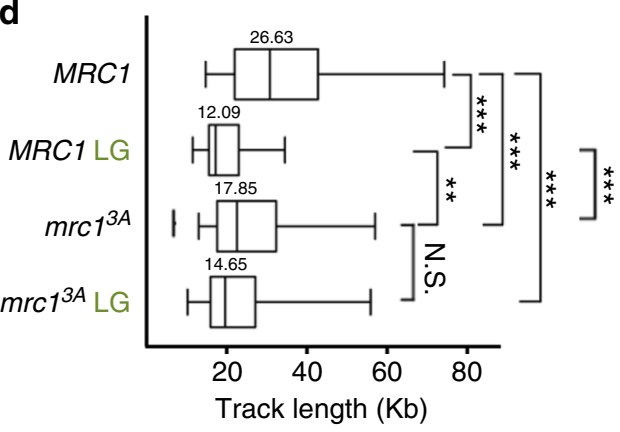

e
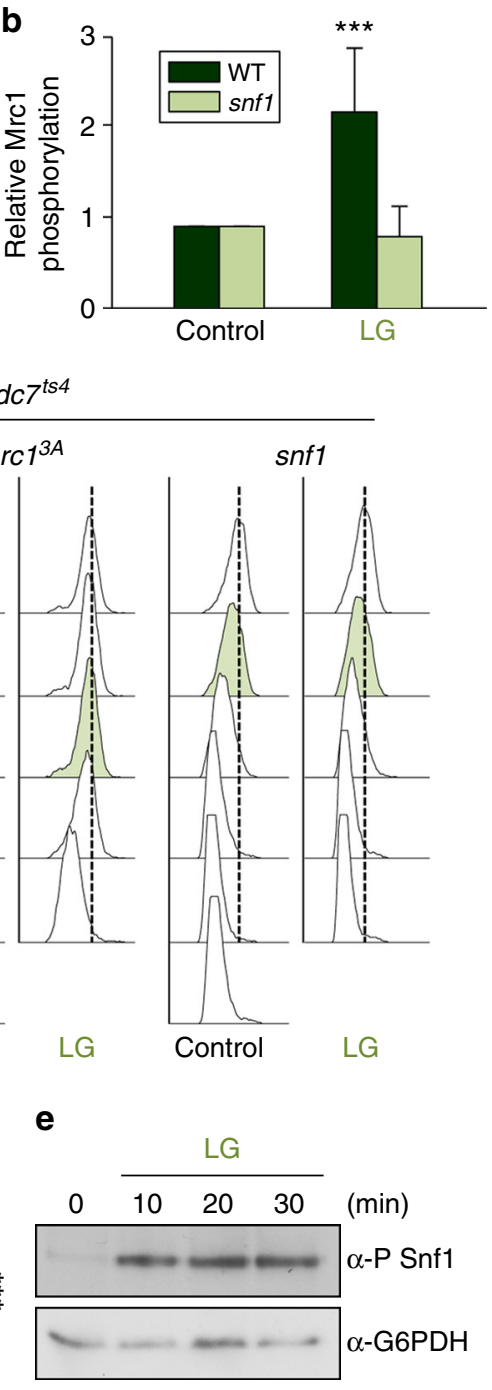

f

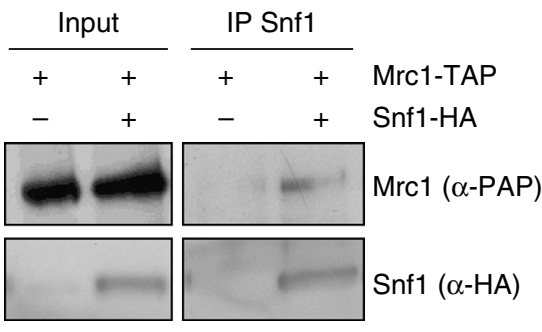

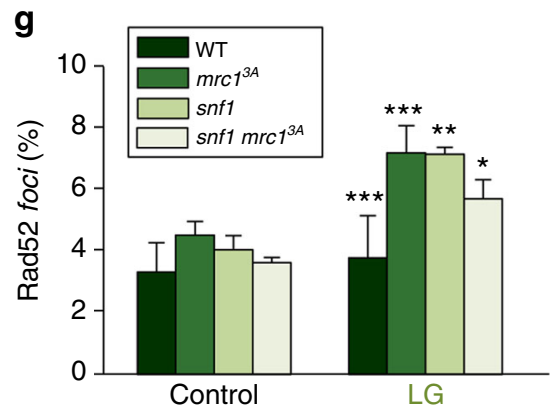


amplified using DH5 $\alpha$-competent cells. Yeast proteins were expressed in BL21competent cells. Each specific strain was grown in LB medium supplemented with ampicillin $(100 \mu \mathrm{g} / \mathrm{ml})$ and/or chloramphenicol $(25 \mu \mathrm{g} / \mathrm{ml})$.

Yeast cells were grown at $25^{\circ} \mathrm{C}$ (except for indicated experiments) in yeast extract peptone dextrose (YPD) or synthetic defined (SD) selective media lacking specific amino acids.

Plasmids. The plasmid pAD88 (MRC1) was obtained by cloning the MRC1 ORF and its promoter ( $323 \mathrm{nt}$ upstream of the ORF) into the BamHI site of the episomal vector pRS415. The plasmid pAD66 $\left(m r \mathrm{Cl}^{3 \mathrm{~A}}\right)$ was obtained by sequential sitedirected mutagenesis of pAD88 phosphorylation sites (Thr169, Ser215, and Ser229) to alanine. The integrative constructs pAD74 (MRC1) and pAD75 $\left(\mathrm{mrcl}^{3 \mathrm{~A}}\right)$ were obtained by BamHI digestion of pAD88 and pAD66, respectively, followed by cloning into the pRS406 integrative vector. Plasmid pAD136 $\left(\mathrm{mrcl}^{3 A}\right)$ contains the $M R C 1^{3 A}$ coding region together with the $M R C 1$ promoter $(323 \mathrm{bp}$ ) and terminator (400 bp downstream of the STOP codon) inserted into the BamHI site of the integrative vector pRS403. Plasmids pMK152 (3MiniAID) and pNHK53 (osTIR1) were used to construct the $c d c 7$-auxin-inducible degron (AID) system ${ }^{46}$. Plasmids pAD58 $(M R C 1)$ and pAD68 $\left(\mathrm{mrcl}^{3 A}\right)$ contain the first $1080 \mathrm{bp}$ of $M R C 1$ or $m r c{ }^{3 A}$, respectively, cloned into the BamHI site of the pGEX-6P-1 vector in frame with the GST N-terminal tag. Plasmids pAD108 (CTT1-IN) and pAD105 (CTT1OUT) are based on the GAL-IN and GAL-OUT vectors, respectively, ${ }^{9}$ and were modified by swapping the GAL1 promoter with the stress-responsive promoter of the CTT1 gene.

Yeast strains. The strains used in this work were derived from W303-1a $(M A T \mathrm{a}$, his3-11,15 leu2-3,112 trp1-1, ura3-1, ade2-1, and can1-100), except for those used for the genomic instability assay or DNA-combing assays, where the $\mathrm{YPh} 277^{47}$ and E3087 (MATa, ade2-1, trp1-1, can1-100, leu2-3,112, his3-11,15, and GAL psi + $R A D 5+)$ strains were used respectively. The Yeast Kinome Screening was performed using TAP-tagged kinases from a yeast TAP-Collection ${ }^{48}$.

To assess in vivo Mrcl phosphorylation assays, we used YAD103 (W303-1a

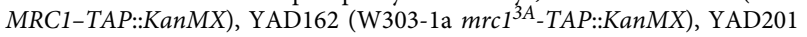
(W303-1a MRC1-TAP::KanMX mpk1::Hyg), and YAD275 (W303-1a MRC1-TAP:: KanMX psk1::Hyg) strains.

For flow cytometric analyses (FACS), western blotting (of Clb5-HA), and chromatin immunoprecipitation (ChIP) assays, we used the following strains: YAD125 (W303-1a $c d c 7-t s 4 m r c 1:: \operatorname{KanMX}$ pAD74::URA), YAD126 (W303-1a cdc7-ts4 mrc1::KanMX pAD75::URA), YAD274 (cdc7-ts4 mrc1::KanMX pAD74:: URA psk1::Hyg), and YAD269 (cdc7-ts4 mrc1::KanMX pAD74::URA snf1::Hyg), these strains were used to synchronize cells at the beginning of $S$ phase by using the $c d c 7-t s 4$ thermosensitive system. Strains YBC15 (W303-1a MRC1-TAP::KanMX pNHK53(StuI)::URA CDC7-3MiniAID::Hygro CLB5-6HA::Nat), YBC16 (W303-1a $m r 1^{3 A}{ }_{-T A P:: K a n M X}$ pNHK53(StuI)::URA CDC7-3MiniAID::Hygro CLB5-6HA:: Nat), and YBC33 (W303-1a MRC1-TAP::KanMX pNHK53(StuI)::URA CDC73MiniAID::Hygro CLB5-6HA::Nat mpk1::TRP1) were used to synchronize cells using the cdc7-AID system. mpkl cells were grown in the presence of an osmoprotectant to prevent cellular lysis.

Strains based on YAD125 and YAD126 were used for DNA-combing experiments upon oxidative stress and glucose starvation. These strains were modified to allow incorporation of exogenous BrdU into genomic DNA. Five copies of the herpes simplex $T K$ gene under the control of the yeast GDP promoter were inserted at the URA3 locus to construct YAD292 (E3087 URA3::URA3/GPDTK(5×) AUR1c::ADH-hENT1) and YAD303 (YAD292 mrc1::Hyg pAD136::HIS). For DNA-combing experiments upon heat stress, the E3087 and yAD303 strains were modified to be synchronized using the $c d c 7-A I D$ system: YBC40 (E3087 URA::HIS pNHK53(StuI)::URA cdc7-MiniAID::Hyg) and YBC45 (YAD303 URA:: LEU pNHK53(StuI)::URA cdc7-MiniAID::Hyg).

The following strains were used to perform recombination assays, microscopy experiments, and northern blot analyses: YAD103, YAD162, and YAD273 (W3031a $m r c 1^{3 A}$-TAP::KanMX $m s n 4:: N a t$ msn2::Hyg), YAD201, YAD200 (W303-1a $m r c 1^{3 A}-T A P:: K a n M X$ mpk1::Hyg), YAD275, YBC1 (W303-1a $m r c 1^{3 A}-T A P::$ KanMX psk1::Hyg), YAD263 (W303-1a MRC1-TAP::KanMX snf1::Hyg), YAD306 (W303-1a $m r c 1^{3 A}$-TAP::KanMX snf1::Hyg), YAD293 (W303-1a MRC1-TAP:: KanMX ssn6::Nat), YAD294 (W303-1a mrc1 $\left.{ }^{3 A}-T A P:: K a n M X ~ s s n 6:: N a t\right)$, and YAY185 (W303-1a hog1::KanMX). To perform recombination assays, the corresponding strains were transformed with either pAD105 or pAD108. To perform microscopy experiments to detect Rad52-YPF foci, the corresponding strains were transformed with the pWJ1344 plasmid.

To perform red-sectoring assays, the YAD146 strain ( $\mathrm{yPH} 277$ mrc1::KanMX) transformed with either pAD88 or pAD66 was used.

To assess protein interactions, the following strains were used: YAD103, YAD211 (W303-1a MPK1-MYC::Hyg), YAD218 (YAD103 MPK1-MYC::Hyg), YAD285 (W303-1a SNF1-6HA::Hyg), YBC7 (YAD103 SNF1-6HA::Hyg), YAD284 (W303-1a PSK1-6HA::Hyg), and YBC8 (YAD103 PSK1-6HA::Hyg). In all cases, tags (-TAP, $-\mathrm{MYC}$, and $-\mathrm{HA}$ ) were integrated at the protein $\mathrm{C}$ terminus.

To assess growth, the following strains were used: YAD103, YAD162, YAD117 (W303-1a sml1 mec1::URA), YAD243 (YAD117 mrcl::KanMX pAD136::HIS), YAD6, and YBC2 strains.

Synchronization and stress conditions. Synchronization of cells at the onset of $S$ phase for FACS, DNA-combing experiments, and chromatin immunoprecipitation (ChIP) assays was performed in two steps. Overnight cultures were diluted at $\mathrm{OD}_{660}=0.3$ and grown for $2 \mathrm{~h}$ at $25^{\circ} \mathrm{C}$ in YPD. In the first step, the cells were incubated with $\alpha$-factor for $2 \mathrm{~h}$ at $25^{\circ} \mathrm{C}(40 \mu \mathrm{g} / \mathrm{ml})$ to presynchronize them in G1 In the second step, the cells were washed and incubated in preheated media at $37^{\circ}$ $\mathrm{C}$ for $2 \mathrm{~h}$ (for $c d c 7^{t s 4}$ cells) or were washed and incubated in media containing 5 $\mathrm{mM}$ indole acetic acid (IAA) (for $c d c 7^{A I D}$ cells) at $25^{\circ} \mathrm{C}$ for $2 \mathrm{~h}$. The cells were then released from the S block to progress into $\mathrm{S}$ phase at $25^{\circ} \mathrm{C}$, in YPD or in the presence of stress. Synchronization of cells at the onset of $S$ phase for recombination assays, red-sectoring assays, or microscopy experiments was performed in a single step. Cells were synchronized at late G1 with $\alpha$-factor $(40 \mu \mathrm{g} / \mathrm{ml})$ for $2 \mathrm{~h}$ at $25^{\circ} \mathrm{C}$, were washed, and were then released at $25^{\circ} \mathrm{C}$ for $35 \mathrm{~min}$ before being subjected to the corresponding stress. Except for the indicated experiments, the cells were subjected to the following stress conditions: oxidative stress $(0.1 \mathrm{mM}$ $\left.\mathrm{H}_{2} \mathrm{O}_{2}\right)$, heat stress $\left(37^{\circ} \mathrm{C}\right)$, osmostress $(0.4 \mathrm{M} \mathrm{NaCl})$, and glucose deprivation (YP- $0.05 \%$ glucose)

Immunoprecipitation assays. The selected strains were grown to mid-log exponential phase $\left(\mathrm{OD}_{660}=1\right)$ and were left unstressed or were stressed as described above except for oxidative stress where cells were stressed in $2 \mathrm{mM} \mathrm{H}_{2} \mathrm{O}_{2}$. The cells were then collected $\left(400 \mathrm{ml}\right.$ per condition) and kept at $-80^{\circ} \mathrm{C}$. Cell pellets were resuspended in $2 \mathrm{ml}$ of lysis buffer ( $45 \mathrm{mM}$ Hepes- $\mathrm{KOH}$ at pH 7.2, $150 \mathrm{mM} \mathrm{NaCl}$, $1 \mathrm{mM}$ EDTA, $10 \%$ glycerol, and $1 \%$ Triton X-100) containing a cocktail of protease and phosphatase inhibitors. An equal volume of glass beads (0.5-mm diameter) was added, and the cells were broken by vortexing at $4^{\circ} \mathrm{C}$. The whole extract was clarified by centrifugation for $10 \mathrm{~min}$ at $9300 \times g$ at $4{ }^{\circ} \mathrm{C}$ and an aliquot was taken as the whole-cell extract (WCE). The extracts $(3-7 \mathrm{mg})$ were first incubated for $3 \mathrm{~h}$ with 1:100 dilutions of anti-Myc antibody (9E10) or with anti-HA antibody (12CA5) and were subsequently incubated overnight with the protein $\mathrm{G}$ affinity matrix (GE Healthcare). For purification of the TAP-tagged proteins, cell extracts were directly incubated with rabbit IgG-Agarose (Sigma) overnight at $4{ }^{\circ} \mathrm{C}$. The agarose beads were then washed 10 times with the lysis buffer. Antibody-bound fractions and the corresponding WCE were boiled in SDS-containing sample buffer and were analyzed using $8 \%$ SDS-PAGE. TAP-tagged proteins were detected with a 1:5 dilution of anti-PAP antibody (p1291 from Sigma).

Fig. $6 \mathrm{Mrc1}$ is phosphorylated by Snf1 upon low glucose availability. a Mrc1 is phosphorylated by Snf1 in vivo. This experiment was carried out as in Fig. 1a. b Quantification of five independent phosphorylation experiments with the indicated strains. Data represent the mean and standard deviation. The graph indicates the relative phosphorylation of $\mathrm{Mrc1}$ (assessed as in $\mathbf{a}$ ) in the indicated strains normalized to the total amount of precipitated Mrc1-TAP protein and then referenced to control conditions. The data represent the mean and standard deviation of five independent experiments. Values that are significantly different (respect to the control conditions) from Student's $t$ test are indicated $\left({ }^{\star \star} p<0.005\right)$. c Phosphorylation of Mrc1 by Snf1 delays DNA replication when the cells are subjected to nutrient deprivation (low glucose), whereas $\mathrm{mrc}^{3 \mathrm{~A}}$ or snf1 mutant cells bypass this delay. Cells were synchronized and released in low glucose (LG), and DNA replication over time was followed using FACS. $\mathbf{d}$ Low glucose delays DNA replication. Replication forks in WT and $\mathrm{mrcl}^{3 \mathrm{~A}}$ cells in control conditions or in LG stress were analyzed using DNA combing. The graph indicates the distribution of BrdU track length (kb) during $1 \mathrm{~h}$ of labeling. Box, 25-75 percentile range; Whiskers, 5-95 percentile range. ${ }^{\star}$ Values are significantly different $\left({ }^{\star \star} p<0.01,{ }^{\star \star \star} p<\right.$ 0.0001). e Snf1 is phosphorylated in vivo upon low glucose. Cells were synchronized and released into $S$ phase in low glucose (LG). Snf1 phosphorylation over time was followed using western blotting with specific antibodies. f Mrc1 and Snf1 interact in vivo. HA-Snf1 was immunoprecipitated (IP) from cells and coprecipitated Mrc1-TAP was assayed using western blotting. $\mathbf{g}$ snf1 and mrc $7^{3 \mathrm{~A}}$ cells show a higher percentage of Rad52-YFP foci upon low glucose. Data represent the mean and standard deviation of three independent experiments. Asterisks indicate statistically significant differences by Student's $t$ test $\left({ }^{\star} p<0.05,{ }^{\star \star} p<0.01,{ }^{\star \star \star} p<0.005\right)$ of stress versus control conditions 
Western blotting. TCA protein extracts were resolved using SDS-PAGE and were then blotted onto a PDVF membrane. Following incubation of the blots with the indicated antibodies, signals were detected using the ECL detection reagent (Amersham). For protein quantification, the corresponding films were scanned using 16 bits/channel and quantified using Quantity One Analysis Software 4.6.1 (BioRad). For resolving Mrc1-TAP mobility shift, $10 \mu \mathrm{M}$ of phostag was added to the 6\% SDS-PAGE gels (37.5:1 acrylamide vs. bisacrylamide).

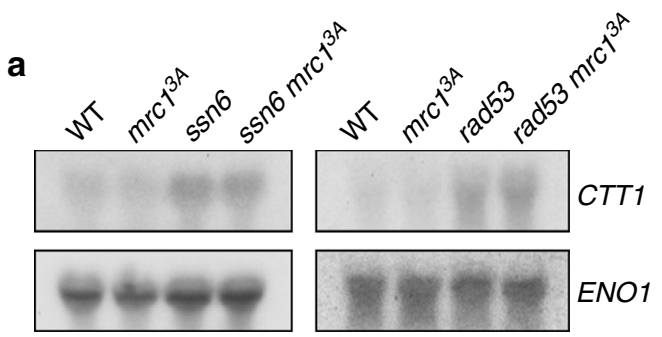

b

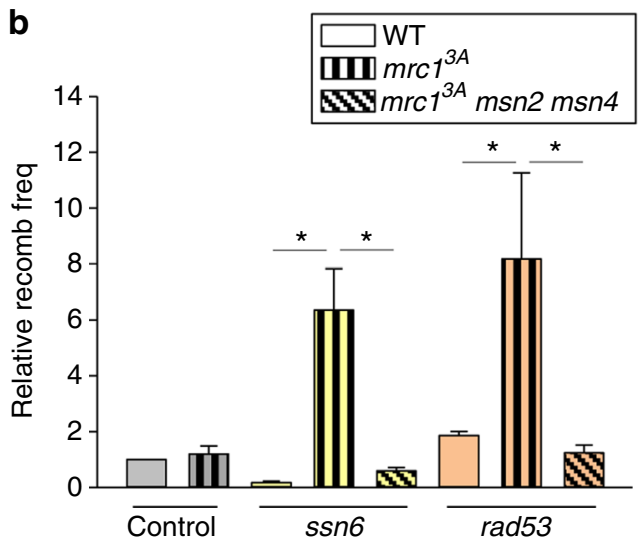

C

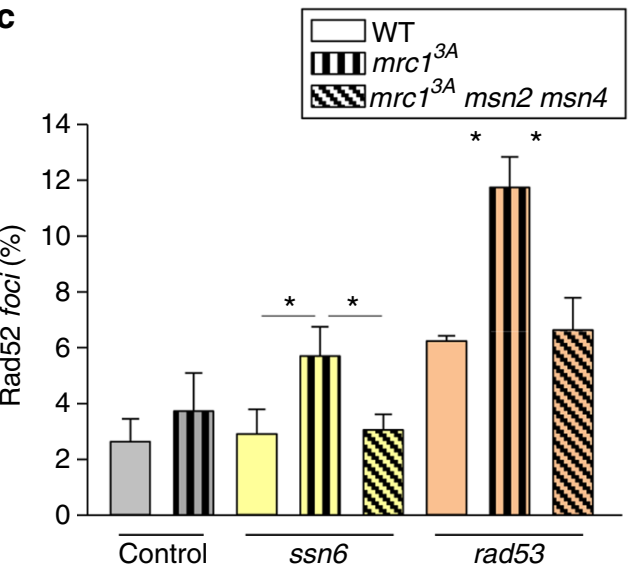

d

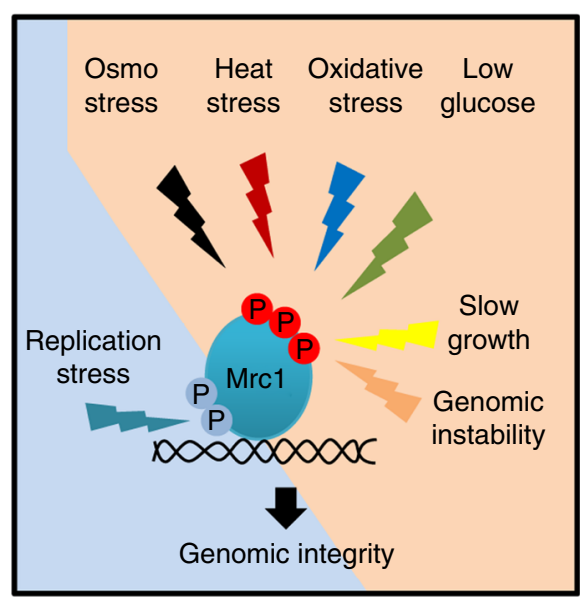

Flow cytometric analysis. For flow cytometric analysis, cells were synchronized at S-phase onset and were released in control conditions or in the presence of stress as described above. Cells were fixed in $70 \%$ ethanol and were then treated overnight with $1 \mathrm{mg} / \mathrm{ml} \mathrm{RNAse} \mathrm{A} \mathrm{at} 37^{\circ} \mathrm{C}$ in $50 \mathrm{mM}$ sodium citrate. Cells were stained with propidium iodide at a final concentration of $4 \mu \mathrm{g} / \mathrm{ml}$ in $50 \mathrm{mM}$ sodium citrate and were analyzed using a FACSCalibur (BD). A total of 10,000 cells were analyzed for each time point using WinMDI 2.9 Software.

DNA combing. Mid-log-phase cells were synchronized as described above and were then pulse-labeled with BrdU (Sigma) after their release into $\mathrm{S}$ phase in the presence (or not) of the specific stress. DNA combing was performed as described $^{49}$. In panel G, cells were synchronized with alpha-factor and then released at $37^{\circ}$ to synchronize them in $\mathrm{S}$ phase given that the strain is cdc7ts; when $\mathrm{H}_{2} \mathrm{O}_{2}$ was added, then cells were incubated at $25^{\circ}$. In contrast, in panel $\mathrm{H}$, cells were not cdc7ts. Instead, they carry a Cdc7 auxin-inducible degron allele, and thus, they were synchronized with alpha-factor and synchronized in S phase by IAA at $25^{\circ}$. Then, they were released at $25^{\circ}$ or $37^{\circ}$ neither with IAA nor with alpha-factor. DNA fibers were extracted in agarose plugs after BrdU labeling and were stretched on silanized coverslips. The DNA fibers were counterstained with anti-ssDNA antibody (DSHB) and a goat anti-mouse antibody coupled to Alexa 546 (A11030, Molecular Probes). BrdU was detected with the BU1/75 (AbCys) anti-BrdU antibody and a goat anti-rat antibody coupled to Alexa 488 (A11006, Molecular Probes). DNA fibers were analyzed using a Leica DM6000 microscope equipped with a DFC390 camera (Leica). Data acquisition was performed with LAS AF (Leica). Even though in panel $\mathrm{H}$ we cannot exclude the possibility of fused replicons, we still observed that replication in $m r c 13 \mathrm{~A}$ is faster at $37^{\circ}$ either because of faster replication forks or activation of origins, indicating that indeed there was an altered DNA replication.

Recombination assays. Selected strains were transformed with either pAD108 (CTT1-IN) or pAD105 (CTT1-OUT) vectors (which contain the origin of replication ARSH4 as indicated in Fig. 2a). Cells were grown up to $\mathrm{OD}_{660}=0.4$ and synchronized as described. Cells were released into $S$ phase and left for $3 \mathrm{~h}$ in a control condition or in the presence of stress, following which $200 \mu$ of the cells were plated in SD $\mathrm{Trp}^{-}$plates (control plates, 1/500 dilution) or in SD $\mathrm{Trp}^{-} \mathrm{Leu}^{-}$ plates (recombination plates, 1/50 dilution). The final recombination levels were calculated as the ratio of recombinant colonies (colonies in SD $\mathrm{Trp}^{-} \mathrm{Leu}^{-}$plates) versus the total number of colonies (colonies in SD $\mathrm{Trp}^{-}$plates).

Red-sectoring plasmid instability assays. Overnight cultures of YAD146 transformed with the plasmid pAD88 or pAD66 were diluted to an $\mathrm{OD}_{660}=0.3$, grown in YPD until an $\mathrm{OD}_{660}=0.5$, and synchronized with $\alpha$-factor $(40 \mu \mathrm{g} / \mathrm{ml})$ for $90 \mathrm{~min}$ at $25^{\circ} \mathrm{C}$. Cells were washed and released into $\mathrm{S}$ phase in YPD for $30 \mathrm{~min}$ and incubated (or not as control) for $3 \mathrm{~h}$ in the presence of stress. Cells $(200 \mu \mathrm{l}$; diluted 1/1000) of each culture were plated in YPD plates and incubated at $30^{\circ} \mathrm{C}$ for 3 days and were then stored at $4^{\circ} \mathrm{C}$ for about 5 days. The final percentage of cells with plasmid loss was calculated as the percentage of red colonies among the total number of colonies (red and white colonies) ${ }^{47}$.

Rad52-YFP foci assay. Rad52-YFP foci were assessed in synchronized cells bearing the plasmid pWJ1344 ${ }^{50}$. Cells were incubated in the presence of stress conditions for $2 \mathrm{~h}$ after 35 -min release from the synchronization with $\alpha$-factor, and the percentage of cells containing Rad52-YFP foci was quantified using a Nikon 90i microscope.

Fig. 7 Mrc1 prevents TAR upon slow growth and genomic instability. a Slow-growing cells (ssn6) and genomically unstable cells (rad53) expressed CTT1 mRNA in the absence of stress. Northern blot analysis of the mRNA expression of CTT1 in the indicated cells is shown. ENO1 mRNA expression was assayed as a loading control (b) ssn 6 and rad53 cells display higher levels of TAR when combined with the $\operatorname{mrc}^{3 \mathrm{~A}}$ allele. Deletion of the MSN2 and MSN4 transcription factors suppresses the high TAR levels of the ssn6 $\mathrm{mrcl}^{3 \mathrm{~A}}$ and $\mathrm{rad53} \mathrm{mrc}^{3 \mathrm{~A}}$ strains. c ssn6 and rad53 cells show a higher percentage of Rad52-YFP foci when combined with the $\mathrm{mrc}^{3 \mathrm{~A}}$ allele. Deletion of the transcription factors suppresses the increase in foci formation in the $s s n 6 \mathrm{mrc}^{3 \mathrm{~A}}$ and $\mathrm{rad} 53 \mathrm{mrcl}^{3 \mathrm{~A}}$ strains. Data represent the mean and standard deviation of three independent experiments. Values that are significantly different $\left({ }^{\star} p<0.05,{ }^{\star \star} p<0.01,{ }^{\star \star \star} p<0.005\right)$ by Student's $t$ test are annotated. d Schematic diagram of the "Mrc1 transcription-replication safeguard mechanism" (MTR). Mrc1 is part of the DNA damage checkpoint that is activated upon replication stress. In addition, the $\mathrm{N}$-terminal phosphorylation of Mrc1 serves to prevent transcription-replication conflicts and to maintain genomic integrity upon transcriptional outbursts during $\mathrm{S}$ phase 
Expression and purification of recombinant proteins. E. coli cells were grown at $37^{\circ} \mathrm{C}$ to an $\mathrm{OD}_{600}=0.5$. GST-tagged proteins were then induced for $6 \mathrm{~h}$ by adding $1 \mathrm{mM} \mathrm{IPTG}$ at $25^{\circ} \mathrm{C}$. After induction, the cells were collected by centrifugation and resuspended in $1 / 50$ th the volume of STET $1 \times$ buffer $(100 \mathrm{mM} \mathrm{NaCl}, 10 \mathrm{mM}$ Tris$\mathrm{HCl}$ at $\mathrm{pH} 8.0,10 \mathrm{mM}$ EDTA at $\mathrm{pH} 8.0$, and $5 \%$ Triton X-100) supplemented with $2 \mathrm{mM}$ DTT, $1 \mathrm{mM}$ PMSF, $1 \mathrm{mM}$ benzamidine, $200 \mu \mathrm{g} / \mathrm{ml}$ leupeptin, and $200 \mu \mathrm{g} / \mathrm{ml}$ pepstatin. Ice-cold cells were lysed by a brief sonication and the lysate was cleared by high-speed centrifugation. GST-fused proteins were pulled down from the supernatants with $300 \mu \mathrm{l}$ of $4 \mathrm{~B}$ gluthatione-sepharose beads (GE Healthcare, 50\% slurry equilibrated with STET $1 \times$ ) by mixing them for $90 \mathrm{~min}$ at $4{ }^{\circ} \mathrm{C}$. The gluthatione-sepharose beads were collected by a brief centrifugation and were washed four times in STET $1 \times$ buffer and twice in $50 \mathrm{mM}$ Tris-HCl buffer at $\mathrm{pH}$ 8.0 supplemented with $2 \mathrm{mM}$ DTT. The GST-fused proteins were then eluted in $200 \mu \mathrm{l}$ of $50 \mathrm{mM}$ Tris-HCl buffer at $\mathrm{pH} 9.5$ supplemented with $2 \mathrm{mM}$ DTT and 10 $\mathrm{mM}$ reduced glutathione (Sigma) by rotating for $30 \mathrm{~min}$ at $4{ }^{\circ} \mathrm{C}$, and were stored at $-80^{\circ} \mathrm{C}$. Wild-type $\mathrm{Mrcl}$ and Mrcl3A proteins, either full length or a peptide comprising the first 360 amino acids, were purified from pAD57, pAD58, pAD67, or pAD68, respectively.

Yeast kinome screening. In total, $123 \mathrm{TAP}$-tagged Ser/Thr kinases were immunoprecipitated from yeast (50 $\mathrm{ml}$ of exponentially growing cultures) as described above (see Immunoprecipitation Assays). Aliquots $(30 \mu \mathrm{l})$ of each kinase bound to IgG beads were divided into two pools that were used to separately assay phosphorylation of an N-terminal fragment (360 amino acids) corresponding to wildtype or Mrcl3A mutant recombinant proteins. The kinase assay was performed as follows: $1 \mu \mathrm{g}$ of GST-MRC1 or GST- $m r c 1^{3 A}$ that was previously purified from $E$. coli was incubated with the IgG bead-bound kinase in $1 \times$ kinase buffer $(50 \mathrm{mM}$ Tris- $\mathrm{HCl}$ at $\mathrm{pH} 7.5,10 \mathrm{mM} \mathrm{MgCl}_{2}$, and $2 \mathrm{mM} \mathrm{DTT)} \mathrm{supplemented} \mathrm{with} 100 \mu \mathrm{M}$ cold ATP and $5 \mu \mathrm{M} \gamma^{32} \mathrm{P}$ ATP. The mixture was incubated for $30 \mathrm{~min}$ at $30^{\circ} \mathrm{C}$ and each kinase assay was resolved by $8 \%$ SDS-PAGE. Proteins were visualized by western blotting and the phosphorylation was detected using Kodak Biomax XAR films (Sigma-Aldrich).

Growth curves. Yeast cultures were grown to saturation overnight and diluted to $\mathrm{OD}_{660}=0.05$ the next morning. Triplicates of the indicated strains were grown in sterile 96-well plates under the indicated stress conditions for $10-15 \mathrm{~h}$ and the $\mathrm{OD}_{660}$ was monitored every hour with the Synergy H1 Hybrid Reader (Biotek).

Northern blotting. Yeast cultures were grown to mid-log phase in YPD and were kept under control conditions or were stressed for $30 \mathrm{~min}$ under the stress conditions as detailed above (see Stress conditions). Total RNA was extracted, resolved in $1 \%$ formaldehyde-containing agarose gels, and transferred to nylon membranes. Transcription of the indicated genes was probed using labeled PCR fragments (High Prime DNA Labeling Kit; Roche). Autoradiographic images were obtained using Kodak Biomax XAR films (Sigma-Aldrich) or a Phosphorimager.

Chromatin immunoprecipitation (ChIP) assay. In ChIP experiments, cells were treated as above, but were released into $\mathrm{S}$ phase at $16^{\circ} \mathrm{C}$ to follow the kinetic association of Dpb2-HA with DNA sequences. Cells (50 $\mathrm{ml}$ per time point) were collected at $\mathrm{OD}_{660}=0.7$ and were treated with $1 \%$ formaldehyde for $20 \mathrm{~min}$ at room temperature. Glycine $(330 \mathrm{mM})$ was then added for $15 \mathrm{~min}$. Cells were collected, were washed four times with ice-cold TBS $(20 \mathrm{mM}$ Tris-HCl, pH 7.5, 150 $\mathrm{mM} \mathrm{NaCl}$ ), and were then kept at $-20^{\circ} \mathrm{C}$ for further processing. Cell pellets were resuspended in $0.3 \mathrm{ml}$ of cold lysis buffer (50 mM HEPES-KOH, pH 7.5, $150 \mathrm{mM}$ $\mathrm{NaCl}, 1 \mathrm{mM}$ EDTA, $1 \%$ Triton X-100, $0.1 \%$ sodium deoxycholate, $0.1 \%$ SDS, and 1 $\mathrm{mM}$ PMSF). An equal volume of glass beads $(0.5 \mathrm{~mm}$ in diameter) was added and the cells were disrupted using Vortex Gene for $13 \mathrm{~min}$ on ice. The lysate was diluted into $0.6 \mathrm{ml}$ of lysis buffer and the glass beads were discarded. The crosslinked chromatin was sonicated to yield an average DNA fragment size of 350 base pairs (bp) (range, 100-850 bp). Finally, the sample was clarified by centrifugation at $16,100 \times g$ for $5 \mathrm{~min}$ at $4{ }^{\circ} \mathrm{C}$. The chromatin solution $(600 \mu \mathrm{l})$ was incubated with $50 \mu \mathrm{l}$ of anti-HA monoclonal antibody precoupled to anti-mouse IgG-conjugated paramagnetic beads (Dynabeads M-450; Dynal). After rotation for $90 \mathrm{~min}$ at $4{ }^{\circ} \mathrm{C}$, the beads were washed twice for $4 \mathrm{~min}$ in $1 \mathrm{ml}$ of lysis buffer, twice in $1 \mathrm{ml}$ of lysis buffer with $500 \mathrm{mM} \mathrm{NaCl}$, twice in $1 \mathrm{ml}$ of washing buffer $(10 \mathrm{mM}$ Tris- $\mathrm{HCl}$, $\mathrm{pH}$ 8.0, $0.25 \mathrm{M} \mathrm{LiCl}, 1 \mathrm{mM}$ EDTA, $0.5 \% \mathrm{~N}-\mathrm{P} 40$, and $0.5 \%$ sodium deoxycholate), and then once in $1 \mathrm{ml}$ of TE (10 mM Tris- $\mathrm{HCl}, \mathrm{pH} 8.0,1 \mathrm{mM}$ EDTA). Immunoprecipitated material was eluted twice from the beads by heating for $10 \mathrm{~min}$ at $65^{\circ} \mathrm{C}$ in $50 \mu \mathrm{l}$ of elution buffer ( $25 \mathrm{mM}$ Tris-HCl, pH 7.5, $10 \mathrm{mM}$ EDTA, and $0.5 \%$ SDS). To reverse cross-linking, samples were adjusted to $0.3 \mathrm{ml}$ with elution buffer and were incubated overnight at $65^{\circ} \mathrm{C}$. After extraction with phenol-chloroform-isoamyl alcohol and chloroform, DNA was ethanol-precipitated for $4 \mathrm{~h}$ at $-20^{\circ} \mathrm{C}$ in the presence of $20 \mu \mathrm{g}$ of glycogen and was resuspended in $30 \mu \mathrm{l}$ of TE buffer. For realtime PCR, oligonucleotides for the ARS727 origin region (ARS727Fwd: GTTCTACTTTAAATGTAGTCAG and ARS727Rev: GAACTGTTCAATACATCAGC) and for CTT1 gene regions (CTT1Fwd: GGAACAAGACCAAATCAGAAACG and CTT1Rev: CTTTGATCTTACAAGCGTGG) were used.
Quantification and statistical analysis. Error bars in bar graphs represent the standard deviation (SD) of three independent experiments. Experiments were performed in triplicate using three biological replicates.

Statistical analysis was performed by using the Student's $t$ test except for the DNA-combing experiments in which statistical analyses were performed using the Mann-Whitney $U$ test, where $p$ values indicated with asterisks were considered significantly different $\left({ }^{*} p<0.05,{ }^{* *} p<0.01\right)$.

The intensity of the bands in western blots was quantified using ImageJ v1.47 (http://imagej.nih.gov/ij).

Data availability. Flow cytometry was performed using the BD FACSCalibur ${ }^{\mathrm{TM}}$ cytometer controlled by the $\mathrm{BD}^{\mathrm{TM}}$ Worklist Manager Software. WinMDi v2.9 software was used to analyze the flow cytometric data.

DNA fibers were analyzed using a Leica DM6000 microscope equipped with a DFC390 camera (Leica). Data acquisition was performed with LAS AF (Leica).

Rad52-YFP fluorescent foci were followed using a Nikon 90i microscope controlled by MetaMorph v7.1.2.0 (Molecular Devices)

Growth curves were constructed using the Synergy H1 Multi-Mode Reader from BioTek controlled by Gen5 ${ }^{\mathrm{TM}}$ v 2.01.14 Software.

ChIP data were analyzed using the ViiA ${ }^{\mathrm{TM}} 7$ Real-Time PCR System controlled by the ViiA 7 RUO Software v1.2 (Applied Biosystems).

All data that support the findings of this study are available from the corresponding authors on request.

Received: 28 February 2017 Accepted: 21 December 2017 Published online: 25 January 2018

\section{References}

1. Hamperl, S. \& Cimprich, K. A. Conflict resolution in the genome: how transcription and replication make it work. Cell 167, 1455-1467 (2016).

2. Garcia-Muse, T. \& Aguilera, A. Transcription-replication conflicts: how they occur and how they are resolved. Nat. Rev. Mol. Cell Biol. 17, 553-563 (2016).

3. Lindahl, T. et al. DNA joining in mammalian cells. Cold Spring Harb. Symp. Quant. Biol. 58, 619-624 (1993).

4. Branzei, D. \& Foiani, M. Maintaining genome stability at the replication fork. Nat. Rev. Mol. Cell Biol. 11, 208-219 (2010).

5. Duch, A., de Nadal, E. \& Posas, F. Dealing with transcriptional outbursts during S phase to protect genomic integrity. J. Mol. Biol. 425, 4745-4755 (2013).

6. Gottipati, P. \& Helleday, T. Transcription-associated recombination in eukaryotes: link between transcription, replication and recombination. Mutagenesis 24, 203-210 (2009).

7. Liu, B. \& Alberts, B. M. Head-on collision between a DNA replication apparatus and RNA polymerase transcription complex. Science 267, 1131-1137 (1995).

8. Deshpande, A. M. \& Newlon, C. S. DNA replication fork pause sites dependent on transcription. Science 272, 1030-1033 (1996).

9. Prado, F. \& Aguilera, A. Impairment of replication fork progression mediates RNA polII transcription-associated recombination. EMBO J. 24, 1267-1276 (2005).

10. Lin, Y. L. \& Pasero, P. Interference between DNA replication and transcription as a cause of genomic instability. Curr. Genome 13, 65-73 (2012).

11. Poli, J. et al. Mec1, INO80, and the PAF1 complex cooperate to limit transcription replication conflicts through RNAPII removal during replication stress. Genes Dev. 30, 337-354 (2016).

12. Bermejo, R., Lai, M. S. \& Foiani, M. Preventing replication stress to maintain genome stability: resolving conflicts between replication and transcription. Mol. Cell 45, 710-718 (2012).

13. de Nadal, E., Ammerer, G. \& Posas, F. Controlling gene expression in response to stress. Nat. Rev. Genet. 12, 833-845 (2011).

14. Lopez-Maury, L., Marguerat, S. \& Bahler, J. Tuning gene expression to changing environments: from rapid responses to evolutionary adaptation. Nat. Rev. Genet. 9, 583-593 (2008).

15. Gasch, A. P. et al. Genomic expression programs in the response of yeast cells to environmental changes. Mol. Biol. Cell 11, 4241-4257 (2000).

16. Nadal-Ribelles, M. et al. Hog1 bypasses stress-mediated down-regulation of transcription by RNA polymerase II redistribution and chromatin remodeling. Genome Biol. 13, R106 (2012).

17. de Nadal, E. \& Posas, F. Osmostress-induced gene expression--a model to understand how stress-activated protein kinases (SAPKs) regulate transcription. FEBS J. 282, 3275-3285 (2015).

18. Yeeles, J. T. et al. How the eukaryotic replisome achieves rapid and efficient dna replication. Mol. Cell 65, 105-116 (2017). 
19. Alcasabas, A. A. et al. Mrc1 transduces signals of DNA replication stress to activate Rad53. Nat. Cell Biol. 3, 958-965 (2001).

20. Osborn, A. J. \& Elledge, S. J. Mrc1 is a replication fork component whose phosphorylation in response to DNA replication stress activates Rad53. Genes Dev. 17, 1755-1767 (2003).

21. Jeong, Y. S. et al. Integrated expression profiling and genome-wide analysis of ChREBP targets reveals the dual role for ChREBP in glucose-regulated gene expression. PLoS ONE 6, e22544 (2011).

22. Yaakov, G. et al. The stress-activated protein kinase Hog1 mediates $S$ phase delay in response to osmostress. Mol. Biol. Cell 20, 3572-3582 (2009).

23. Duch, A. et al. Coordinated control of replication and transcription by a SAPK protects genomic integrity. Nature 493, 116-119 (2013).

24. Pardo, B., Crabbe, L. \& Pasero, P. Signaling pathways of replication stress in yeast. FEMS Yeast Res. https://doi.org/10.1093/femsyr/fow101 (2017).

25. Shirayama, M. et al. APC(Cdc20) promotes exit from mitosis by destroying the anaphase inhibitor Pds1 and cyclin Clb5. Nature 402, 203-207 (1999).

26. Jacobson, M. D. et al. Testing cyclin specificity in the exit from mitosis. Mol. Cell Biol. 20, 4483-4493 (2000).

27. Aguilera, A. The connection between transcription and genomic instability. EMBO J. 21, 195-201 (2002).

28. Causton, H. C. et al. Remodeling of yeast genome expression in response to environmental changes. Mol. Biol. Cell 12, 323-337 (2001).

29. Kamada, Y. et al. The protein kinase C-activated MAP kinase pathway of Saccharomyces cerevisiae mediates a novel aspect of the heat shock response. Genes Dev. 9, 1559-1571 (1995).

30. Huang, M. et al. PSK1 regulates expression of SOD1 involved in oxidative stress tolerance in yeast. FEMS Microbiol. Lett. 350, 154-160 (2014).

31. De Wever, V. et al. A dual role for PP1 in shaping the Msn2-dependent transcriptional response to glucose starvation. EMBO J. 24, 4115-4123 (2005).

32. Celenza, J. L. \& Carlson, M. A yeast gene that is essential for release from glucose repression encodes a protein kinase. Science 233, 1175-1180 (1986).

33. Jiang, R. \& Carlson, M. Glucose regulates protein interactions within the yeast SNF1 protein kinase complex. Genes Dev. 10, 3105-3115 (1996).

34. Wilson, W. A., Hawley, S. A. \& Hardie, D. G. Glucose repression/derepression in budding yeast: SNF1 protein kinase is activated by phosphorylation under derepressing conditions, and this correlates with a high AMP:ATP ratio. Curr. Biol. 6, 1426-1434 (1996).

35. McCartney, R. R. \& Schmidt, M. C. Regulation of Snf1 kinase. Activation requires phosphorylation of threonine 210 by an upstream kinase as well as a distinct step mediated by the Snf4 subunit. J. Biol. Chem. 276, 36460-36466 (2001).

36. O'Duibhir, E. et al. Cell cycle population effects in perturbation studies. Mol. Syst. Biol. 10, 732 (2014).

37. Torres, E. M. et al. Effects of aneuploidy on cellular physiology and cell division in haploid yeast. Science 317, 916-924 (2007).

38. Sheltzer, J. M. et al. Transcriptional consequences of aneuploidy. Proc. Natl Acad. Sci. USA 109, 12644-12649 (2012).

39. Posas, F. et al. The transcriptional response of yeast to saline stress. J. Biol. Chem. 275, 17249-17255 (2000).

40. Nadal-Ribelles, M. et al. Control of Cdc28 CDK1 by a stress-induced lncRNA. Mol. Cell 53, 549-561 (2014).

41. Gonzalez-Novo, A. et al. Hog1 targets Whi5 and Msal transcription factors to down-regulate cyclin expression upon stress. Mol. Cell Biol. 35, 1606-1618 (2015).

42. Clotet, J. \& Posas, F. Control of cell cycle in response to osmostress: lessons from yeast. Methods Enzymol. 428, 63-76 (2007)

43. Woods, A. et al. Yeast SNF1 is functionally related to mammalian AMPactivated protein kinase and regulates acetyl-CoA carboxylase in vivo. J. Biol. Chem. 269, 19509-19515 (1994).

44. Gunjan, A. \& Verreault, A. A Rad53 kinase-dependent surveillance mechanism that regulates histone protein levels in S. cerevisiae. Cell 115, 537-549 (2003).
45. Hoch, N. C. et al. Molecular basis of the essential s phase function of the rad53 checkpoint kinase. Mol. Cell Biol. 33, 3202-3213 (2013).

46. Nishimura, K. et al. An auxin-based degron system for the rapid depletion of proteins in nonplant cells. Nat. Methods 6, 917-922 (2009).

47. Spencer, F. et al. Mitotic chromosome transmission fidelity mutants in Saccharomyces cerevisiae. Genetics 124, 237-249 (1990).

48. Ghaemmaghami, S. et al. Global analysis of protein expression in yeast. Nature 425, 737-741 (2003).

49. Bianco, J. N. et al. Analysis of DNA replication profiles in budding yeast and mammalian cells using DNA combing. Methods 57, 149-157 (2012).

50. Lisby, M., Mortensen, U. H. \& Rothstein, R. Colocalization of multiple DNA double-strand breaks at a single Rad52 repair centre. Nat. Cell Biol. 5, 572-577 (2003).

\section{Acknowledgements}

We thank Dr Taro Nakamura (NBRP, Japan) for the plasmids pNHK53 and pMK152. B.C. is a recipient of an FPI fellowship. The study was supported by grants from the Spanish Ministry of Economy and Competitiveness (BFU2015-64437-P and FEDER, BFU2014-52125-REDT, and BFU2014-51672-REDC to F.P.; BFU2014-52333-P and FEDER to E.N.; and BFU2013-42918 and FEDER to A.A.), the Andalusian Government (P12-BIO-1238), ERC2014-ADG669898 TARLOOP, and Worldwide Cancer Research 15-0098 to A.A. and the Catalan Government (2014 SGR 599), and the Fundación Botín, by Banco Santander through its Santander Universities Global Division to F.P. F.P. and E.d.N. are recipients of an ICREA Acadèmia (Generalitat de Catalunya).

\section{Author contributions}

A.D., B.C., S.I.B., M.G.-R., and G.S. designed and performed the experiments; A.D., B.C., A.A., E.d.N., and F.P. participated in experimental design, data analysis, and writing the article.

\section{Additional information}

Supplementary Information accompanies this paper at https://doi.org/10.1038/s41467017-02756-x.

Competing interests: The authors declare no competing financial interests.

Reprints and permission information is available online at http://npg.nature.com/ reprintsandpermissions/

Publisher's note: Springer Nature remains neutral with regard to jurisdictional claims in published maps and institutional affiliations.

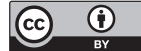

Open Access This article is licensed under a Creative Commons Attribution 4.0 International License, which permits use, sharing, adaptation, distribution and reproduction in any medium or format, as long as you give appropriate credit to the original author(s) and the source, provide a link to the Creative Commons license, and indicate if changes were made. The images or other third party material in this article are included in the article's Creative Commons license, unless indicated otherwise in a credit line to the material. If material is not included in the article's Creative Commons license and your intended use is not permitted by statutory regulation or exceeds the permitted use, you will need to obtain permission directly from the copyright holder. To view a copy of this license, visit http://creativecommons.org/ licenses/by/4.0/

(c) The Author(s) 2018 